\title{
First Effort at Constructing a High-Density Photosynthetically Active Radiation Dataset during 1961-2014 in China
}

\author{
Wenmin Qin, Lunche Wang, Ming Zhang, AND Zigeng NiU \\ Hubei Key Laboratory of Critical Zone Evolution, School of Earth Sciences, and School of Geography and \\ Information Engineering, China University of Geosciences, Wuhan, China
}

MING LUO

School of Geography and Planning, and Guangdong Key Laboratory for Urbanization and Geo-simulation, Sun Yat-sen University, Guangzhou, China

AIWEN LIN

School of Resource and Environmental Science, Wuhan University, Wuhan, China

Bo Hu

Institute of Atmospheric Physics, Chinese Academy of Sciences, Beijing, China

(Manuscript received 6 September 2018, in final form 22 January 2019)

\begin{abstract}
Photosynthetically active radiation (PAR) is a key factor for vegetation growth and climate change. Different types of PAR models, including four physically based models and eight artificial intelligence (AI) models, were proposed for predicting daily PAR. Multiyear daily meteorological parameters observed at 29 Chinese Ecosystem Research Network (CERN) stations and 2474 Chinese Meteorological Administration (CMA) stations across China were used for testing, validating, and comparing the above models. The optimized back propagation (BP) neural network based on the mind evolutionary algorithm (MEA-BP) was the model with highest accuracy and strongest robustness. The correlation coefficient $R$, mean absolute bias error (MAE), and RMSE for MEA-BP were $0.986,0.302 \mathrm{MJ} \mathrm{m}^{-2}$ day $^{-1}$ and $0.393 \mathrm{MJ} \mathrm{m}^{-2}$ day $^{-1}$, respectively. Then, a high-density PAR dataset was constructed for the first time using the MEA-BP model at 2474 CMA stations of China. A quality control process and homogenization test (using RHtestsV4) for the PAR dataset were further conducted. This high-density PAR dataset would benefit many climate and ecological studies.
\end{abstract}

\section{Introduction}

Photosynthetically active radiation (PAR) is the solar radiation in the spectral range of $400-700 \mathrm{~nm}$, which is a key factor in many ecological and agricultural processes, especially in plant photosynthesis (Wang et al. 2013). Accurate observation and estimation of PAR is crucial for a large number of studies (Hoyle et al. 2009). In China, the Chinese Ecosystem Research Network (CERN) could provide PAR observations with high quality at only 36 stations, as the site density was still too sparse for ecological and meteorological studies on large scales. Numerous PAR products were produced using satellite signals based

\footnotetext{
Corresponding author: Lunche Wang,wang@cug.edu.cn
}

on atmospheric radiative transfer models (Tang et al. 2017). The Total Ozone Mapping Spectrometer (TOMS) could provide a monthly mean PAR product with $1^{\circ} \times 1^{\circ}$ pixel resolution (Eck and Dye 1991). Pinker and Laszlo (1992) generated the ISCCP-BR and ISCCP-PL PAR products with high temporal resolution using measurements from International Satellite Cloud Climatology Project (ISCCP). Many other sensors also provided PAR estimates for a wide range of application; for example, MODIS MOD22 provided instantaneous PAR records over global oceans ( $\mathrm{Li}$ et al. 2015); however, the spatial continuity and accuracy were limitations for the applications of these PAR records.

Numerous models have been developed for the estimation of PAR. The deterministic models assumed that 
PAR was a part of surface solar radiation (SSR); for example, Moon (1940) revealed that the ratio between surface PAR and surface shortwave solar radiation (RPAR) was approximately 0.440; McCree (1966) further noted that RPAR changed in varying climatic conditions, being $0.47-0.52$ in clear-sky conditions and $0.5-0.58$ in cloudy-sky conditions. Yu et al. (2015) evaluated the accuracy of 10 statistical models at seven sites of Surface Radiation Budget Network (SRBN). However, the above statistical models did not consider the atmospheric radiation transfer processes that were unable to incorporate the changing parameters in remote regions. Physical models (including broadband models and spectral models) provided an effective way to estimate PAR, taking into account the atmospheric dumping processes in the spectral range of 400-700 nm. Gueymard (1989) developed a physically based irradiance model (CPCR2) for estimating solar radiation between 0.29 and $2.7 \mu \mathrm{m}$. Compared with broadband models, spectral models have higher spectral resolution, for example, Gueymard (1995) introduced an upgraded spectral radiation model (SMARTS2) for estimating solar radiation at 0.28$4.0 \mu \mathrm{m}$; and Wandji Nyamsi et al. (2015) introduced an approach for PAR estimation $(0.4-0.7 \mu \mathrm{m}$, divided into 12 intervals). Alados et al. (1996) showed that SMARTS2 performed better than SPCTRAL2 in Granada due to the flexibility concerning the selection of aerosol types.

Remote sensing was an alternative way to estimate PAR on large scales; for example, polar-orbiting satellites (Terra, Aqua, Landsat, etc.) could provide essential observations for modeling PAR with higher spectral and spatial resolutions. Nasahara (2009) proposed a simplified PAR model with spatial resolution of $250 \mathrm{~m}$ using MODIS products; the relative error of daily estimated PAR was $27 \%$. Singh et al. (1987) estimated PAR using the IRS-P4 Ocean Color Monitor (OCM) onboard OceanSat-1, and the root-mean-square error (RMSE) was $21.28 \mathrm{~W} \mathrm{~m}^{-2}$. By combining the cloud transmittance parameterizations provided by Sun et al. (2012) and the clear-sky parameterizations developed by Qin et al. (2012), Tang et al. (2017) presented an alternative way to get continuous information of PAR at regional and global scales using MODIS products. However, these models using polar-orbiting satellites were restricted by the relatively poor temporal resolutions. Li et al. (2012) proposed an efficient parameterization to retrieve hourly PAR using both satellite signals from MTSAT-1R and MODIS, which significantly improved the temporal and spatial resolutions. Liang et al. (2006) developed a model based on the look-up table (LUT) method and atmospheric radiation transfer model for incident PAR using MODIS products; the relative error was about $9.95 \%$ at seven validation sites. Liang et al. (2007) further improved this method by combining MODIS and Geostationary Operational Environmental Satellite (GOES) data. It was proved that this method was more accurate than the interpolation method. Zhang et al. (2014) generated the Global Land Surface Satellite (GLASS) PAR products during 2008-10 based on an improved LUT method using satellite signals derived from MODIS products, the Meteosat Second Generation (MSG2) SEVIRI, MTSAT-1R, and GOES Imager.

Artificial intelligence (AI) is a popular and promising method for retrieving PAR in recent years. Among the AI models, artificial neural networks (ANNs) such as multilayered perceptron (MLP) models were the most frequently used. López et al. (2001) applied MLP to predict hourly PAR using temperature, relative humidity, dewpoint temperature, and precipitable water vapor $w$ measurements. Wang et al. (2016a,b) compared three ANN methods for hourly PAR estimation and found that MLP and radial basis neural network (RBNN) models showed better performances than generalized regression neural network (GRNN) models at different ecosystems. Feng et al. (2018) compared AI methods and physical models for forecasting PAR, and the results showed that the improved back propagation neural network model using the genetic algorithm was superior to other PAR models.

Many studies have been conducted for estimating PAR over mainland China in recent years. Tang et al. (2013) constructed PAR datasets throughout China for the most recent 50 years using meteorological measurements at 716 stations based on Qin's PAR model (Qin et al. 2012), where the mean bias error (MBE), RMSE, and $R^{2}$ were $2.4 \mathrm{~W} \mathrm{~m}^{-2}, 14.0 \mathrm{~W} \mathrm{~m}^{-2}$, and 0.92 , respectively. Many LUT models for estimating PAR have also been applied in China (Liang et al. 2006, 2007; Zheng and Liang 2011). Further work is needed to evaluate the accuracy and robustness of different PAR models over mainland China using nationwide longterm CERN observations under various sky conditions.

This study attempted to make a comprehensive study on the model accuracies of 12 selected PAR models, including a broadband model (BBM) using meteorological measurements, an efficient physically based parameterization (EPP) using MODIS products, a physically based model (PBM) using MODIS and MTSAT products, a LUT model, and eight AI models. Daily PAR observations at 29 CERN stations across China were used for evaluating the accuracy and robustness of these PAR models. Then, by applying the model with highest accuracy and strongest robustness to the 2474 CMA stations, a high-density dataset of daily PAR over China during 1961-2014 was constructed for the first time. The quality control processes and homogenization test on the PAR dataset were further conducted. This high-density 


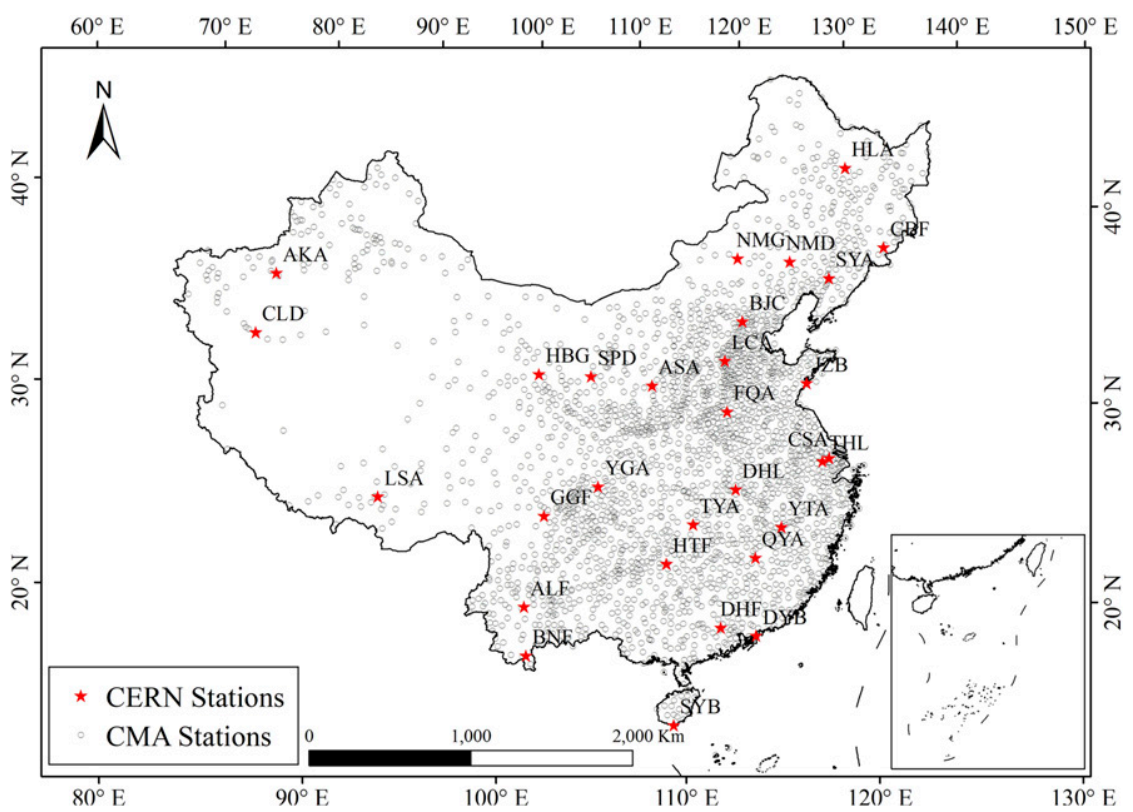

FIG. 1. Spatial distributions of the CERN and CMA stations used in this study.

PAR dataset would be a reliable dataset for the studies of solar energy, land surface ecosystems, and climate change on large scales.

\section{Data and methods}

\section{a. Data}

\section{1) Meteorological measurements}

In situ meteorological observations-including maximum air temperature (Tmax), dewpoint temperature (TD), surface temperature (Tg), vapor pressure (HB), air pressure $(P)$, sea level pressure $(\mathrm{P} 0)$, minimum air temperature (Tmin), wind speed (WD), relative humidity (RH), precipitation (PRE), mean air temperature $(T)$, sunshine duration (SD), visibility (VIS), global solar radiation $(\mathrm{Eg})$, reflected solar radiation $(\mathrm{Er})$, net solar radiation $(\mathrm{Ec})$, extraterrestrial solar radiation (Exg), and PAR measurements at 29 CERN stations
(2006-16) and 2474 CMA stations (1961-2014) over mainland China-were collected and preprocessed for developing and evaluating above 12 PAR models. As shown in Fig. 1, these meteorological stations (from CERN and CMA) were distributed in various climate zones with distinctive terrain patterns.

\section{2) SAtellite Data}

The MTSAT and MODIS products were used to retrieve PAR for EPP, PBM, and LUT in this study. Atmospheric parameters could be derived from two instantaneous observations (1030 and $1330 \mathrm{LT})$ by MODIS. The surface albedo $\rho_{g}$ and Earth-atmosphere albedo $\rho_{B}$ were derived from MTSAT data. Detailed information on MODIS products and MTSAT data is presented in Table 1.

\section{3) Climate zones}

The climatic zoning data provided by the Resource and Environment Science Data Center of the Chinese

TABLE 1. Basic information about the MODIS and MTSAT products used in this study.

\begin{tabular}{llcc}
\hline \multicolumn{1}{c}{ Dataset name } & \multicolumn{1}{c}{ Parameters } & Spatial resolution & Temporal resolution \\
\hline MTSAT (VIS) & Earth-atmosphere albedo & $0.05^{\circ}$ & Hourly \\
MOD04/MYD04 & Aerosol optical depth (AOD) & $5 \mathrm{~km}$ & Daily \\
MOD06/MYD06 & Cloud phase optical thickness (CPO), solar zenith angle $h$, & $1 \mathrm{~km}$ & Daily \\
& $\quad$ cloud water path (CWP), effective particle radius (re), & & \\
cloud fraction (TCP) & $5 \mathrm{~km}$ & \\
MOD07/MYD07 & Precipitable water vapor $w$, total ozone amount (Ioz) & $0.05^{\circ}$ & Daily \\
MTSAT-1R & Surface albedo $\rho_{g}$ & $1^{\circ}$ & Hourly \\
MOD08_D3/MYD08_D3 & AOD, $h$, CWP, re, TCP, $w$, Ioz & Daily \\
\hline
\end{tabular}



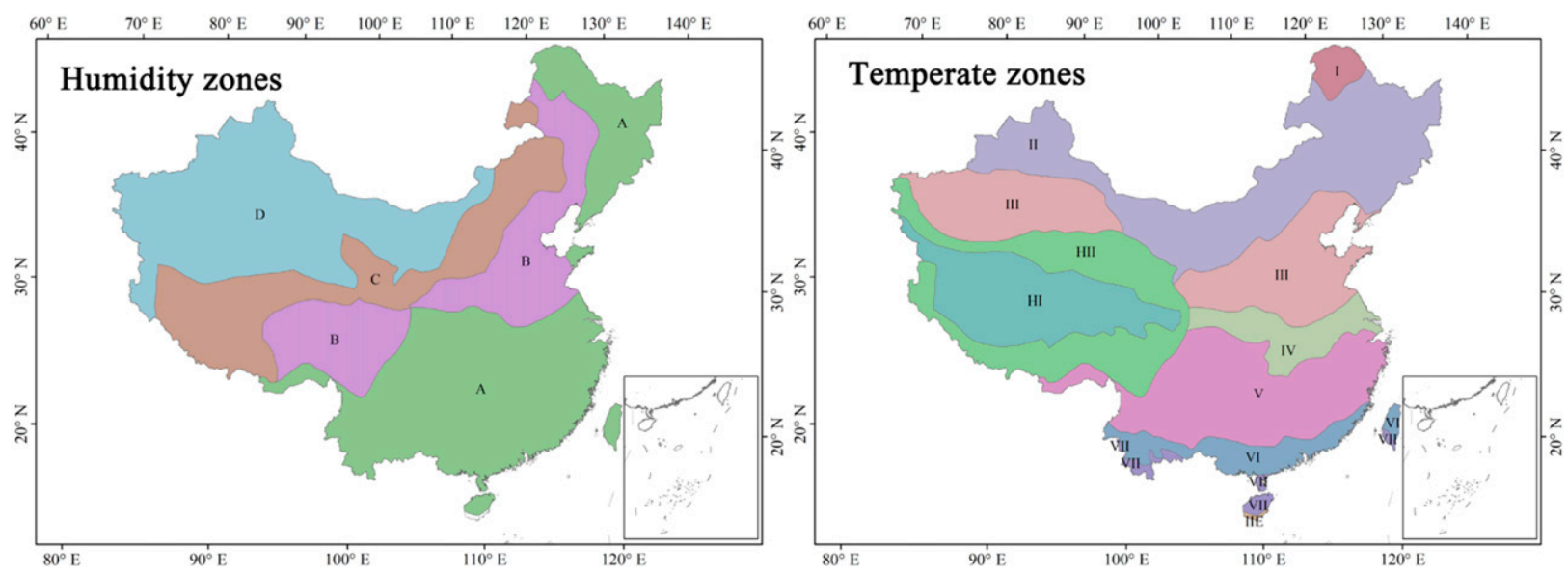

FIG. 2. The humidity zones and temperature zones in China (A for humid, B for semihumid, C for semiarid, D for arid; I for cold temperate, II for midtemperate, III for warm temperate, IV for north subtropical zone, V for the midsubtropics, VI for the south subtropics, VII for the edge of tropical zone, HI for plateau subfrigid zone, HII for plateau temperate zone, and IIE for midtropical zone with humid weather).

Academy of Sciences were used for validating the accuracy and robustness of different PAR models in different climate zones. As shown in Fig. 2, there are 10 temperature zones and 4 humidity zones across China.

\section{b. PAR estimation models}

\section{1) Physically Based Models \\ (i) $B B M$}

This broadband model was developed for retrieving PAR using meteorological observations based on the spectral transmittance equations for different radiation dumping processes (aerosol scattering, aerosol extinction, water vapor absorption, etc.) (Qin et al. 2012). The $\mathrm{PAR}$ in the BBM model is expressed as

$$
Q_{g, a}^{\mathrm{all}}=\tau_{c} Q_{g, a}^{\mathrm{clr}},
$$

$$
\begin{aligned}
Q_{g, a}^{\mathrm{clr}} & =\frac{1}{\Delta t} \int Q_{g, i}^{\mathrm{clr}} d t, \\
Q_{g, i}^{\mathrm{clr}} & =Q_{b, i}^{\mathrm{clr}}+Q_{d, i}^{\mathrm{clr}}, \quad \text { and } \\
\tau_{c} & =0.2495+1.1415 \mathrm{ratio}+0.3910 \mathrm{ratio}^{2},
\end{aligned}
$$

where $Q_{g, a}^{\text {all }}$ and $Q_{g, a}^{\mathrm{clr}}$ are the mean PAR estimates under all-sky and clear-sky conditions, respectively. The terms $Q_{b, i}^{\mathrm{clr}}, Q_{d, i}^{\mathrm{clr}}$, and $Q_{g, i}^{\mathrm{clr}}$ are the direct, diffuse, and global instantaneous PAR in clear-sky conditions, respectively. The term $\tau_{c}$ represents the cloud effect on PAR; the term ratio is the sunshine hours (sd). A detailed description of BBM models can be found in Qin et al. (2012).

\section{(ii) $P B M$}

The PBM model attempted to estimate PAR in a tropical environment based on the analysis of all depletion processes and reflections between the atmosphere and the Earth surface. The instantaneous PAR was expressed as follows:

$$
I_{\mathrm{PAR}}=\frac{I_{\mathrm{TOA}}\left[1-\rho_{B}-\left(1-\tau_{o}\right)-\tau_{o}\left(\alpha_{w}+\alpha_{\mathrm{aer}}+\alpha_{g}\right)\right]}{\left(1-\rho_{g}\right)+\rho_{g}\left(\alpha_{w}+\alpha_{\mathrm{aer}}+\alpha_{g}\right)+\rho_{g}\left(1-\alpha_{w}-\alpha_{\mathrm{aer}}-\alpha_{g}\right)\left(1-\tau_{\mathrm{o}}\right)},
$$

where $\rho_{g}$ and $\rho_{B}$ represent the surface and Earthatmosphere albedo, respectively; $\tau_{o}$ denotes the transmittance due to ozone; $\alpha_{g}, \alpha_{w}$, and $\alpha_{\text {aer }}$ represent the absorbance by mixed gasses, $w$, and aerosol particles; and $I_{\text {TOA }}$ denotes the extraterrestrial PAR at the top of atmosphere (TOA). The term $I_{\mathrm{TOA}}$ can be expressed as

$$
I_{\mathrm{TOA}}=S_{c}[1+0.033 \cos (2 \pi \mathrm{jday} / 365)] \cos \theta,
$$

where jday denotes the Julian day number since 1 January, $h$ indicates the solar zenith angle, and $S_{c}$ represents the solar constant ( $400-700 \mathrm{~nm})$. Also, $\tau_{o}$ and $\alpha_{g}$ can be calculated using the following equations: 


$$
\begin{gathered}
\tau_{o}=\frac{\int_{0.4 \mu \mathrm{m}}^{0.7 \mu \mathrm{m}} I_{o \lambda} \tau_{o \lambda} d \lambda}{\int_{0.4 \mu \mathrm{m}}^{0.7 \mu \mathrm{m}} I_{o \lambda} d \lambda}, \\
a_{w}=1-\frac{\int_{0.4 \mu \mathrm{m}}^{0.7 \mu \mathrm{m}} I_{o \lambda} \tau_{w \lambda} d \lambda}{\int_{0.4 \mu \mathrm{m}}^{0.7 \mu \mathrm{m}} I_{w \lambda} d \lambda}, \\
a_{g}=1-\frac{\int_{0.4 \mu \mathrm{m}}^{0.7 \mu \mathrm{m}} I_{o \lambda} \tau_{g \lambda} d \lambda}{\int_{0.4 \mu \mathrm{m}}^{0.7 \mu \mathrm{m}} I_{g \lambda} d \lambda},
\end{gathered}
$$

where $I_{O \lambda}$ is the spectral extraterrestrial solar radiation. The spectral transmittances by ozone $\tau_{o \lambda}$, water vapor $\tau_{w \lambda}$, and mixed gasses $\tau_{g \lambda}$ can be expressed as follows:

$\tau_{o \lambda}=\exp \left(-k_{o \lambda} \operatorname{lm}_{r}\right)$,

$\tau_{w \lambda}=\exp \left[-0.2385 k_{w \lambda} w m_{r} /\left(1+20.07 k_{w \lambda} w m_{r}\right)^{0.45}\right], \quad$ and

$\tau_{g \lambda}=\exp \left[-1.41 k_{g \lambda} m_{a} /\left(1+118.93 k_{g_{\lambda}} m_{a}\right)^{0.45}\right]$,

where $l$ denotes the total ozone amount $(\mathrm{cm}) ; m_{r}$ and $m_{a}$ represent a relative and absolute air mass, respectively. Detailed description about the PBM model can be found in Janjai and Wattan (2011).

\section{(iii) $E P P$}

Following the work by Qin et al. (2012) and Sun et al. (2012), Tang et al. (2017) proposed an EPP using MODIS products. The PAR in all-sky conditions can be calculated as

$$
\begin{aligned}
& \mathrm{PAR}_{\text {all }} \\
& =\frac{\left(1-\mathrm{CF}_{\mathrm{wc}}-\mathrm{CF}_{\mathrm{ic}}\right) \mathrm{PAR}_{\mathrm{clr}}+\mathrm{CF}_{\mathrm{wc}} \mathrm{PAR}_{\mathrm{wc}}+\mathrm{CF}_{\mathrm{ic}} \mathrm{PAR}_{\mathrm{ic}},}{1-\rho_{a, \mathrm{all}} \rho_{g}},
\end{aligned}
$$

where $\mathrm{CF}_{\mathrm{wc}}$ and $\mathrm{CF}_{\mathrm{ic}}$ are the cloud fractions (CF) under water cloudy (wc) sky conditions and ice cloudy (ic) sky conditions, respectively. The terms $\mathrm{PAR}_{\mathrm{clr}}, \mathrm{PAR}_{\mathrm{ic}}$, and $\mathrm{PAR}_{\mathrm{wc}}$ were the PAR for clear sky, ic sky, and wc sky conditions, respectively; $\rho_{g}$ represents the surface albedo. The term $\rho_{a \text { all }}$ is the atmospheric spherical albedo, expressed as follows:

$$
\rho_{\text {all }}=\left(1-\mathrm{CF}_{\mathrm{wc}}-\mathrm{CF}_{\mathrm{ic}}\right) \rho_{\mathrm{clr}}+\mathrm{CF}_{\mathrm{wc}} \rho_{\mathrm{wc}}+\mathrm{CF}_{\mathrm{ic}} \rho_{\mathrm{ic}} .
$$

A detailed description of the EPP model can be found in Tang et al. (2017).

\section{(iv) LUT}

Zhang et al. (2014) generated the GLASS PAR products using satellite signals based on the look-up table method and atmospheric radiation transfer model. Both satellite signals from polar-orbiting and geostationary satellites were used in this model. First, the geometric correction, reprojection, and calibration processes for satellite images were conducted. Second, the look-up table 1 was generated to connect atmospheric parameters ( $w, \mathrm{AOD}$, and $l$, etc.) to $I_{\text {TOA }}$. Third, the look-up table 2 was generated to connect the atmospheric parameters to PAR measurements. Finally, the PAR was retrieved using look-up table 1 and look-up table 2. Detailed descriptions of the LUT method can be found in Zhang et al. (2014) and Liang et al. (2013). In this study, the GLASS PAR products during 2008-10 and 2013 over mainland China were directly used.

\section{2) ARtificial INTELLIGENCE MODELS}

In this study, eight artificial intelligence models, including the back propagation neural network (BP), multivariate adaptive regression splines (MARS), optimized BP based on the genetic algorithm (Genetic), M5 Model Tree (M5Tree), least squares support vector machine (LSSVM), optimized extreme learning machine based on particle swarm optimization (PSO-ELM), the adaptive neuro-fuzzy inference system (ANFIS), and optimized BP neural network based on the mind evolutionary algorithm (MEA-BP) were selected for estimating PAR. Meteorological parameters (including relative humidity, air temperature, air pressure, etc.) were the input variables for these AI models; PAR observations at 29 CERN stations were the output values for these models. In this study, $70 \%$ of the dataset was randomly chosen for training stages and the remaining $30 \%$ for testing stages.

\section{(i) $B P$}

$\mathrm{BP}$ models are the most popular artificial intelligence models for predicting PAR with strong robustness and high accuracy (Wang et al. 2016a,b). Figure 3a illustrates the basic structure of BP models that were used in this study. There are three layers in BP models, the input layer, hidden layer, and output layer, which consist of some neurons connected to each other. Detailed descriptions about the BP model for estimating PAR can be found in Feng et al. (2018).

\section{(ii) ANFIS}

ANFIS is an efficient hybrid AI system for solving nonlinear regression problems based on Takagi-Sugeno fuzzy inference system (Jang 1991). The neural network was adopted to realize the fuzzification, fuzzy reasoning, and antifuzzification in ANFIS (Zou et al. 2017). The 


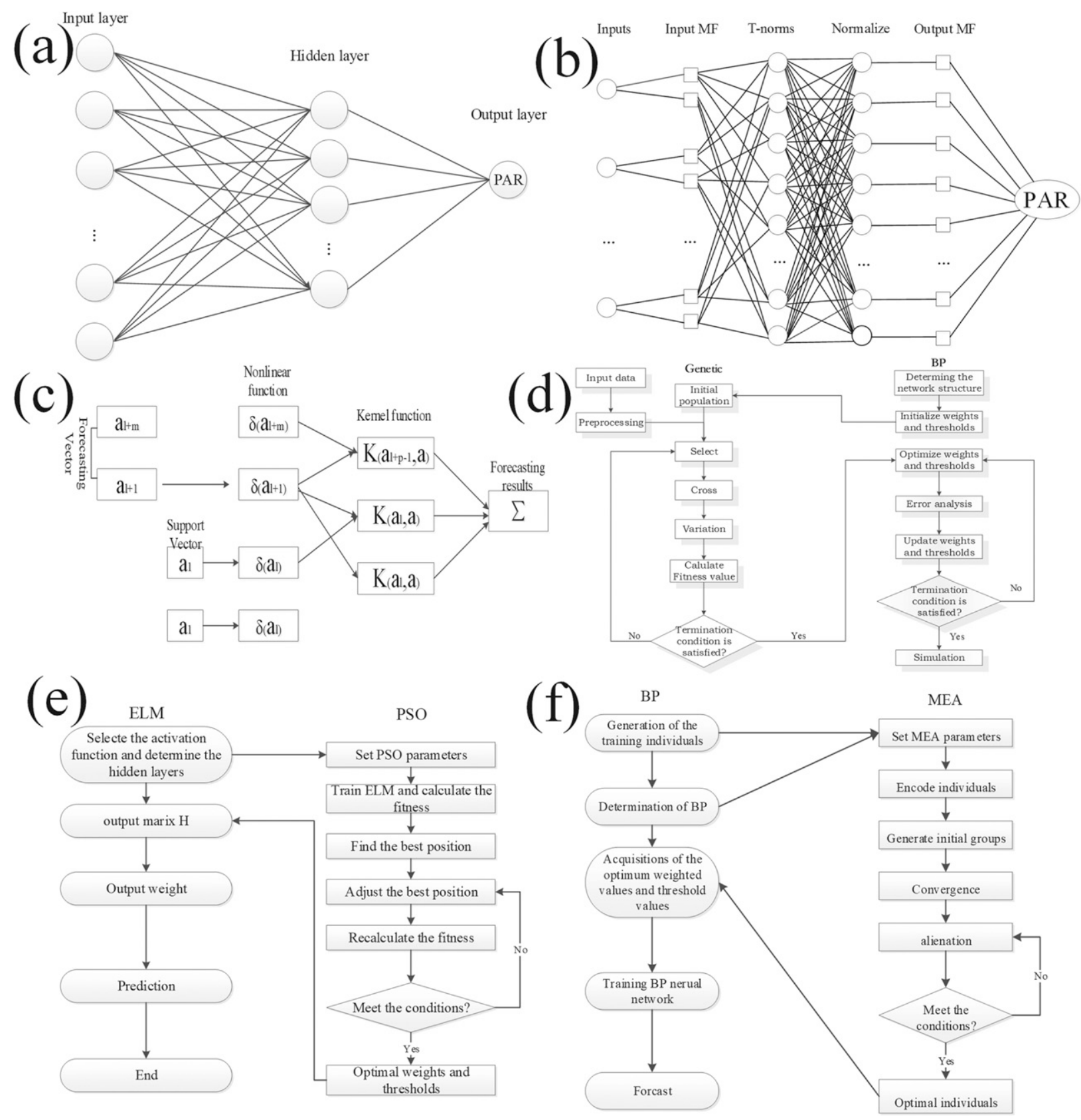

FIG. 3. The general structures of the (a) BP, (b) ANFIS, (c) LSSVM, (d) Genetic, (e) PSO-ELM, and (f) MEA-BP models.

basic schematic architecture of ANFIS is illustrated in Fig. 3b. A detailed description of the ANFIS for estimating PAR can be found in Jang (1991).

\section{(iii) LSSVM}

LSSVM is a least squares version for support vector machine (Kumar and Kar 2009), which is an efficient method for nonlinear regression problems. Detailed steps in the LSSVM model are illustrated in Fig. 3c. The detailed LSSVM procedure can be found in Kisi (2014).

\section{(iv) Genetic}

The Genetic algorithm, often abbreviated simply as $\mathrm{GA}$, is an evolutionary algorithm to deal with optimization and search problems inspired by Darwin's biological evolution theory (Holland 1962, 1992). In this study, the thresholds and weights in BP neural network would be optimized using Genetic model estimations. The detail procedures for Genetic models were illustrated in Fig. 3d. More detail steps about the Genetic model can be found in Feng et al. (2018). 


\section{(v) M5Tree}

The M5 Model Tree was an improved decision tree for nonlinear regression problems, which was first developed by Quinlan (2006). The M5Tree would be used to reveal the mathematical relationships between input parameters and PAR. The M5Tree for estimating PAR can be conducted following four main steps (Rahimikhoob et al. 2013; Solomatine and Xue 2004): 1) the decision trees were created by splitting data into subsets; 2 ) the model tree was generated; 3) the linear regression model between input parameters and PAR measurements was built; 4) the PAR values were retrieved using M5Tree.

\section{(vi) $M A R S$}

Multivariate adaptive regression splines is a form of a nonparametric regression method introduced by Friedman (1991), which could be used to deal with complex and highdimensional regression problems (Friedman 1991; Samui 2012). In this study, an open source package in Matlab code (ARESlab) incorporating the MARS technique was used for estimating PAR. Detailed code and procedures for the MARS model were provided by Gints Jēkabsons (http:// www.cs.rtu.lv/jekabsons/regression.html).

\section{(vii) PSO-ELM}

The extreme learning machine can be used for solving regression problem with a single layer or multiple layers of hidden nodes (Huang et al. 2006, 2012). In this study, an Optimized ELM model using particle swarm optimization method was used to adjust the thresholds and weights of ELM to improve the accuracy in estimating PAR. The detailed steps of PSO-ELM are shown in Fig. 3e.

\section{(viii) $M E A-B P$}

The MEA-BP model, an optimized BP model based on the mind evolutionary algorithm, was introduced for predicting PAR, combining the local searching ability of the BP neural network and the global searching ability of the MEA (Ying et al. 2017). Detailed steps of MEABP are shown in Fig. 3f (Zhao et al. 2016).

\section{c. Quality control for PAR observations and estimations}

The quality control procedures for PAR observations can be achieved following two rules (Wang et al. 2015). First, the ratio between PAR and SSR should be higher than $1.3 \mathrm{~mol} \mathrm{MJ}^{-1}$ and lower than $2.8 \mathrm{~mol} \mathrm{MJ}^{-1}$; second, the surface observed PAR should not be higher than the $I_{\mathrm{TOA}}$ at the same geographical location $\left(\mathrm{PAR}_{0}\right)$, otherwise it will be directly deleted in this study. For PAR estimates, the estimated PAR that exceeded the $\mathrm{PAR}_{0}$ was replaced by the mean values in the nearby days. The $\mathrm{PAR}_{0}$ could be obtained from the SSR arrived at the TOA $\left(G_{0}\right)$. The term $G_{0}$ was calculated using following equation:

$G_{0}=24 S_{0} L_{0}[(\pi / 180) \gamma(\sin \delta \sin \phi)+(\cos \delta \cos \phi \sin \gamma)] \pi$,

where $\gamma$ is the sunrise hour angle, $L_{0}$ is Earth's orbit correction factor, $\phi$ represents geographic latitude, $\delta$ is the solar declination angle, and $S_{0}$ is the solar constant $\left(1367 \mathrm{~W} \mathrm{~m}^{-2}\right)$. Moreover, the instantaneous PAR measurement is using the unit of photon flux density $\left(\mathrm{mol} \mathrm{MJ}^{-1}\right)$. Dye (2004) considered that the photosynthetic photon flux density (PPF) could be converted to an energy flux density (EFD) by dividing by a constant (4.57). Therefore, the unit of PAR measurements that were used in this study was unified from PPF to EFD by dividing by 4.57 .

\section{d. Homogenization test}

In this study, the homogenization test of the PAR dataset is conducted using the RHtestsV4 software package (Wang 2008; Wang et al. 2010). The RHtestsV4 is the extended version of RHtestsV2 and RHtestsV3 with the addition of the provision of quantile matching adjustments, which has been widely used for the homogeneity for historic dataset. The relative test based on the penalized maximal $T$ (PMT) test and the absolute test based on the penalized maximal $F$ (PMF) test were two main methods for detecting and adjusting the changepoints in the historical dataset. Given the relative sparse CERN stations in China, not enough reliable reference datasets could be used for the PMT test. Thus, the PMF test was used for homogenization of the PAR dataset.

\section{e. Mean impact value test}

The mean impact value (MIV) test was proposed by Dombi et al. (1995) to find the most representative variables for AI models. The MIV test was conducted as follows (Gao et al. 2017):

1) Data preparations for training AI models. The input data samples $P_{j}(j=1,2,3, \ldots, n)$ for AI models should be normalized. Then, two new training samples $P_{j 1}(10 \%$ higher than the original input data samples) and $P_{j 2}(10 \%$ lower than the original input data samples) for each variable were generated.

2) Training AI models. The AI models were trained using normalized data. Then, two new PAR outputs $A_{j 1}$ and $A_{j 2}$ using $P_{j 1}$ and $P_{j 2}$ were calculated in the well-trained models, respectively.

3) Calculating MIV scores. The difference (IV) between the PAR outputs using $P_{j}$ and two new PAR outputs $\left(A_{j 1}\right.$ and $\left.A_{j 2}\right)$ for each variable should be 
calculated. Then the MIV scores (the cumulative contribution rate of IV for each independent variable) were calculated.

4) Variables selection. The variables with relatively higher absolute MIV scores should be set as the optimal input variables for AI models.

\section{f. Bayesian optimization}

For AI models, the optimization or tuning process on the hyperparameters (learning rate and hidden neurons size, etc.) is a key step to get optimal estimations (Claesen and De Moor 2015). Different approaches such as grid search (GS), random search (RS), and Bayesian optimization (BOP) have been applied for hyperparameter optimization (Bergstra et al. 2011). The Bayesian optimization performed better than GS and RS, owing to its strong ability to the quality of experiments (Snoek et al. 2012). The Bayesian optimization for hyperparameters was conducted as follows:

1) Normalize the input data samples for AI models.

2) Define a train split to use inside the objective function.

3) Define hyperparameters to optimize and set a function handle.

4) Optimize hyperparameters using the "bayesop" function in Matlab 2018b and find the best hyperparameters.

\section{g. Statistical indicators}

The mean absolute bias error (MAE), RMSE $\left(\mathrm{MJ} \mathrm{m}^{-2} \mathrm{day}^{-1}\right)$, and correlation coefficient $R$ were the main statistic indicators for the evaluation of the accuracy of the above PAR models:

$$
\begin{gathered}
\mathrm{RMSE}=\sqrt{\left[\sum_{i=1}^{N}\left(\mathrm{PAR}_{e, i}-\mathrm{PAR}_{o, i}\right)^{2}\right] / N, \quad(14)} \\
\mathrm{MAE}=\left[\sum_{i=1}^{N} \mid\left(\mathrm{PAR}_{e, i}-\mathrm{PAR}_{o, i}\right)\right] / N, \quad \text { and } \\
R=\frac{\left(\sum_{i=1}^{N} \mathrm{PAR}_{o, i}-\overline{\mathrm{PAR}_{o, i}}\right)\left(\mathrm{PAR}_{o, i}-\overline{\mathrm{PAR}_{e, i}}\right)}{\sqrt{\left(\sum_{i=1}^{N} \mathrm{PAR}_{o, i}-\overline{\mathrm{PAR}_{o, i}}\right)^{2} \sqrt{\left(\mathrm{PAR}_{o, i}-\overline{\mathrm{PAR}_{e, i}}\right)^{2}}}}
\end{gathered}
$$

where $\mathrm{PAR}_{e . i}$ means the estimated PAR $\left(\mathrm{MJ} \mathrm{m}^{-2} \mathrm{day}^{-1}\right)$, $\mathrm{PAR}_{o . i}$ means the observed PAR $\left(\mathrm{MJ} \mathrm{m}^{-2} \mathrm{day}^{-1}\right)$, $\overline{\mathrm{PAR}_{e, i}}$ is the mean value of estimated PAR $\left(\mathrm{MJ} \mathrm{m}^{-2} \mathrm{day}^{-1}\right), \overline{\mathrm{PAR}_{o, i}}$ is the mean value of observed
PAR ( $\mathrm{MJ} \mathrm{m}^{-2} \mathrm{day}^{-1}$ ), and $N$ indicates the number of data samples.

\section{Results and discussion}

\section{a. Variable selection and parameter tuning for AI models}

Nineteen parameters including Tmax, Tmin, $T$, TD, Tg, HB, $P$, P0, WD, RH, PRE, SD, VIS, Eg, Er, Ec, Exg, altitude $A$, and jday were used as input parameters for the variable selection and parameter tuning processes. A total of 1000 meteorological records were randomly selected for the variable selection and parameter tuning test. The MIV method was used for the variable selection of AI models. Table 2 shows the MIV scores for different AI models. Figure 4 illustrates the distribution of the absolute MIV scores for different AI models. The result showed that Eg was always the variable with the highest MIV scores, because PAR is the main component of Eg. In contrast, PRE showed small impacts on the estimated results of the AI models. However, Eg, TD, P0, Tg, and Er were not routinely measured at the $2474 \mathrm{CMA}$ stations that were used in this study. Therefore, considering data accessibility, only seven parameters, RH, $T$, PS, SD, $A$, jday, and Exg, with high absolute MIV scores were finally used as the input parameters for the AI models.

Then, the Bayesian optimization method for the parameter tuning of AI models was conducted. Here, we take the BP model as an example to show the process of finding the ideal hidden layer size and learning rate for AI models. The parameter tuning tests for other AI models were also conducted using the Bayesian optimization method. As an illustration, the varieties of hidden layer size and learning rate versus RMSE for the BP model are shown in Fig. 5. The results indicate that the ideal hidden layer size and learning rate for the BP model are 10 and 0.0010025 , respectively.

\section{b. Validation of daily PAR estimations}

Figure 6 shows the RMSE, MAE, and $R$ for all physically based models and AI models. For physical models, BBM performed better than PBM, EPP, and LUT with RMSE, $R$, and MAE of $1.158 \mathrm{MJ} \mathrm{m}^{-2} \mathrm{day}^{-1}, 0.912$, and $0.973 \mathrm{MJ} \mathrm{m}^{-2}$ day $^{-1}$, respectively, due to its strict radiation transferring theoretical basis. PBM was the model with largest model deviations; the RMSE and MAE for the PBM model were much higher than other models. The RMSE, $R$, and MAE for LUT were $2.156 \mathrm{MJ} \mathrm{m}^{-2} \mathrm{day}^{-1}$, 0.576 , and $1.624 \mathrm{MJ} \mathrm{m}^{-2} \mathrm{day}^{-1}$, respectively. Affected by cloud cover, atmospheric parameters (AOD, $w$, and $l$ ) derived from MODIS Level 2 atmosphere products for EPP were not always available and reliable at all CERN 
TABLE 2. The MIV scores for different AI models.

\begin{tabular}{|c|c|c|c|c|c|c|c|c|}
\hline Variables & BP & ANFIS & M5Tree & Genetic & MARS & LSSVM & PSO-ELM & MEA-BP \\
\hline $\mathrm{Eg}$ & 0.0792 & 0.1141 & 0.1149 & 0.0790 & 0.0999 & 0.0643 & 0.0916 & 0.0961 \\
\hline TD & 0.0417 & 0.0520 & 0.0478 & 0.0516 & 0.0253 & 0.0531 & 0.0443 & 0.0312 \\
\hline$P$ & 0.0342 & 0.0264 & 0.0188 & 0.0217 & 0.0280 & 0.0246 & 0.0175 & 0.0328 \\
\hline $\mathrm{P} 0$ & -0.0310 & -0.0242 & -0.0164 & -0.0320 & -0.0363 & -0.0294 & -0.0225 & -0.0235 \\
\hline $\mathrm{Tg}$ & -0.0301 & -0.0266 & -0.0386 & -0.0244 & -0.0224 & -0.0178 & -0.0179 & -0.0243 \\
\hline$T$ & 0.0238 & 0.0285 & 0.0165 & 0.0336 & 0.0307 & 0.0253 & 0.0129 & 0.0344 \\
\hline SD & -0.0236 & -0.0339 & -0.0286 & -0.0295 & -0.0129 & -0.0218 & -0.0345 & -0.0286 \\
\hline $\mathrm{RH}$ & -0.0190 & -0.0173 & -0.0263 & -0.0197 & -0.0280 & -0.0232 & -0.0095 & -0.0242 \\
\hline Exg & 0.0183 & 0.0145 & 0.0180 & 0.0184 & 0.0271 & 0.0214 & 0.0179 & 0.0104 \\
\hline $\mathrm{Er}$ & -0.0151 & -0.0224 & -0.0143 & -0.0160 & -0.0175 & -0.0103 & -0.0199 & -0.0172 \\
\hline$A$ & 0.0105 & 0.0128 & 0.0124 & 0.0073 & 0.0095 & 0.0068 & 0.0094 & 0.0110 \\
\hline jday & -0.0056 & -0.0073 & -0.0065 & -0.0039 & -0.0076 & -0.0041 & -0.0054 & -0.0037 \\
\hline $\mathrm{HB}$ & 0.0051 & 0.0026 & 0.0073 & 0.0034 & 0.0026 & 0.0055 & 0.0071 & 0.0069 \\
\hline Tmin & 0.0041 & 0.0026 & 0.0057 & 0.0036 & 0.0026 & 0.0032 & 0.0042 & 0.0051 \\
\hline VIS & 0.0038 & 0.0042 & 0.0036 & 0.0049 & 0.0035 & 0.0024 & 0.0047 & 0.0034 \\
\hline WD & 0.0032 & 0.0043 & 0.0017 & 0.0035 & 0.0032 & 0.0023 & 0.0047 & 0.0047 \\
\hline Tmax & 0.0030 & 0.0019 & 0.0035 & 0.0030 & 0.0040 & 0.0034 & 0.0016 & 0.0020 \\
\hline $\mathrm{Ec}$ & -0.0013 & -0.0011 & -0.0008 & -0.0018 & -0.0007 & -0.0014 & -0.0008 & -0.0017 \\
\hline PRE & -0.0001 & -0.0001 & -0.0001 & -0.0001 & -0.0002 & -0.0002 & -0.0001 & -0.0002 \\
\hline
\end{tabular}

stations. Thus, the model deviations of EPP were also large; the RMSE, $R$, and MAE for EPP were $1.583 \mathrm{MJ} \mathrm{m}^{-2}$ day $^{-1}$, 0.795 and $1.316 \mathrm{MJ} \mathrm{m}^{-2}$ day $^{-1}$, respectively. It was clear that AI models performed better than physically based models, which may be due to their strong self-learning abilities. Among all AI models, the MEA-BP model performed better than the other PAR models with RMSE, $R$, and MAE values of $0.392 \mathrm{MJ} \mathrm{m}^{-2} \mathrm{day}^{-1}, 0.986$, and $0.301 \mathrm{MJ} \mathrm{m}^{-2}$ day $^{-1}$, respectively, which may be due to its excellent optimization method on the thresholds and weights of the BP neural network. On the whole, the MEABP model was the most accurate PAR model among all selected PAR models.

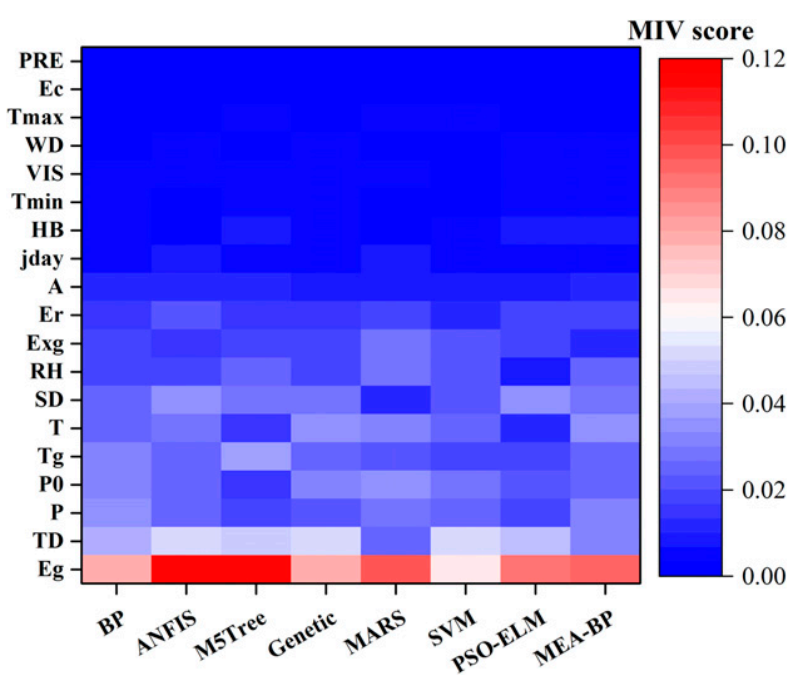

FIG. 4. The absolute MIV scores for different AI models.
The spatial distributions of RMSE and MAE for all 12 selected PAR models are shown in Tables 3 and 4, respectively. For physically based models, relatively larger errors occurred in the south Yangtze River area, which may be due to a complicated atmospheric transfer process (rainy and cloudy sky conditions); for instance, the MEAN1 values (defined as the mean value of RMSE for all physical models) of the RMSE and MAE for TYA were 2.395 and $2.127 \mathrm{MJ} \mathrm{m}^{-2} \mathrm{day}^{-1}$, respectively. Large model deviations were also found in the Qinghai-Tibet Plateau owing to the changing weather and strong heating of the atmosphere; for instance, the MEAN1 values of the RMSE and MAE in LSA were 2.055

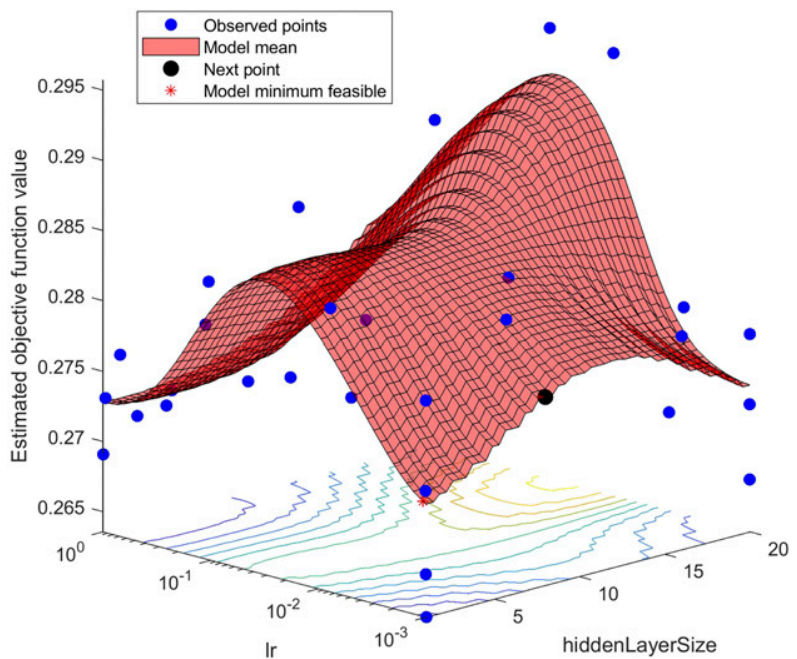

FIG. 5. Variation of hidden layer size and learning rate vs the estimated objective function for the BP model. 

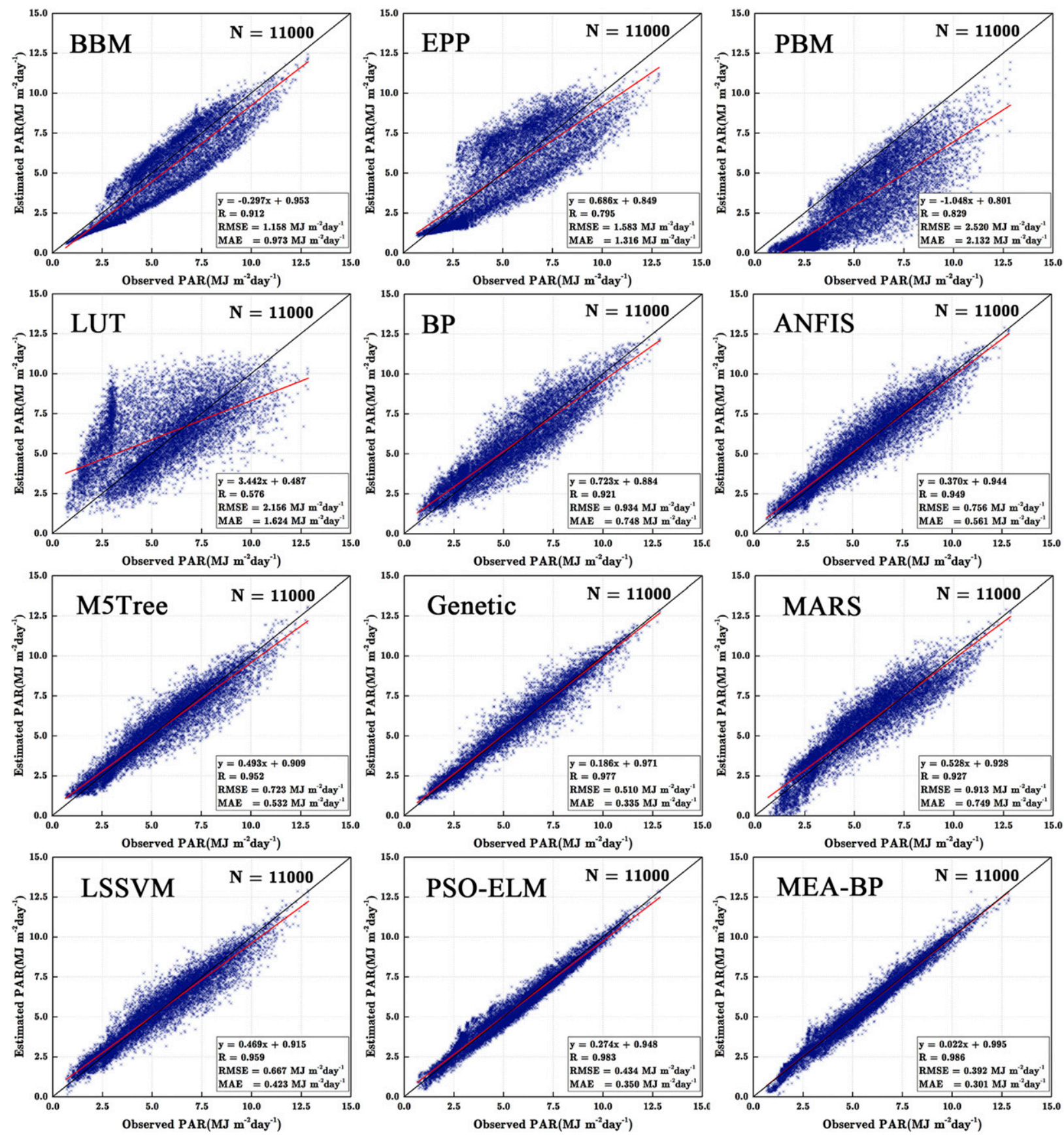

FIG. 6. Comparison between the observed and estimated PAR at CERN stations using different models.

and $1.725 \mathrm{MJ} \mathrm{m}^{-2}$ day $^{-1}$, respectively. In contrast, relatively lower model deviations were mainly found in northwestern China, owing to the relatively weak radiation dumping processes there; for instance, the MEAN1 of the RMSE and MAE at AKA were 1.489 and $1.154 \mathrm{MJ} \mathrm{m}^{-2} \mathrm{day}^{-1}$, respectively. It was clear that the AI models showed overwhelming accuracy and greater robustness than physically based models with lower RMSE and MAE at all CERN stations. Among them, the Genetic, PSO-ELM, and MEA-BP models had the highest accuracy and strongest robustness at all CERN stations.

Figure 7 showed the monthly variations of the statistical indicators evaluating the model accuracy for all selected PAR models. For physically based models, the largest model deviations were in summer because of the 


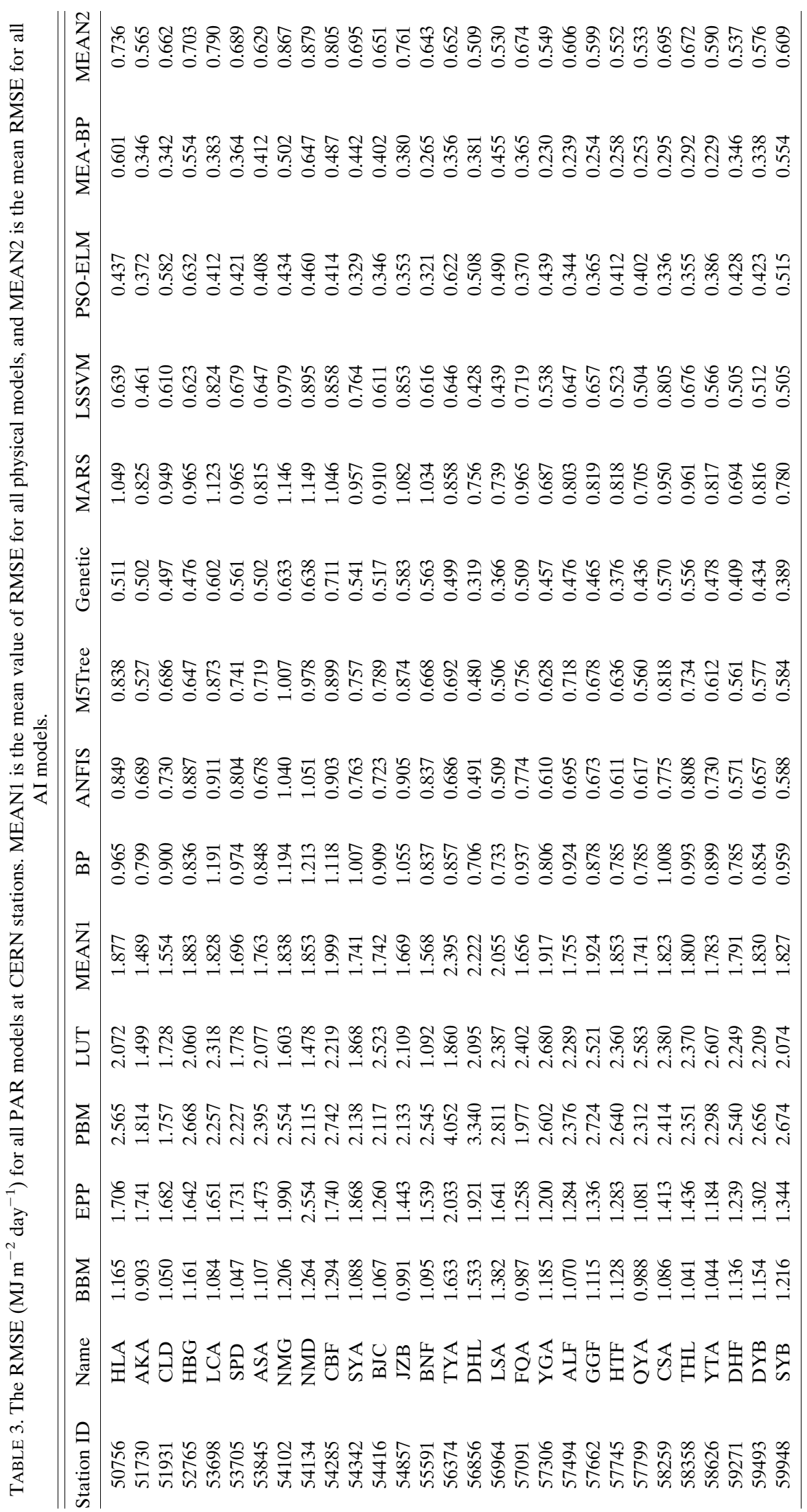




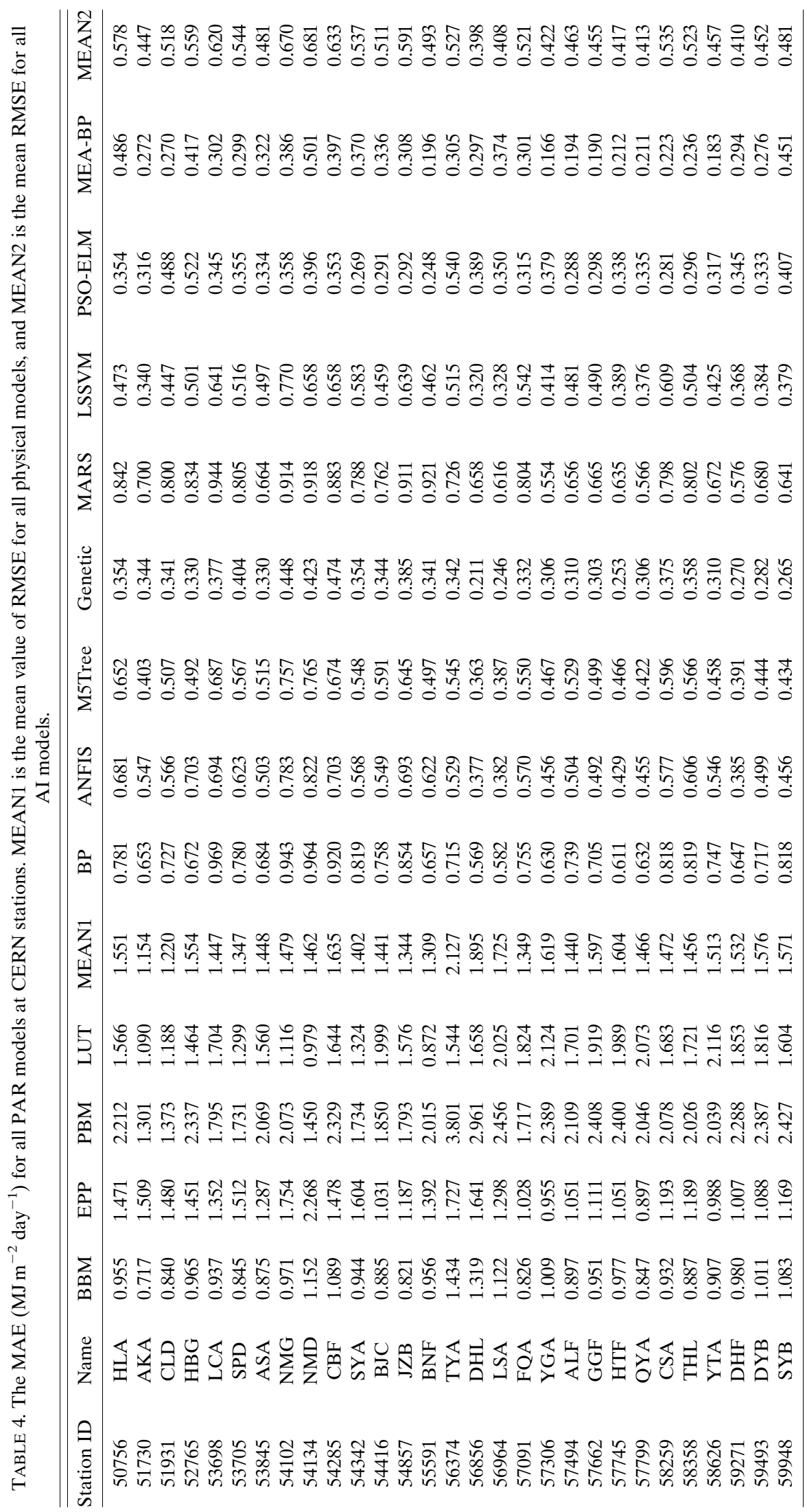



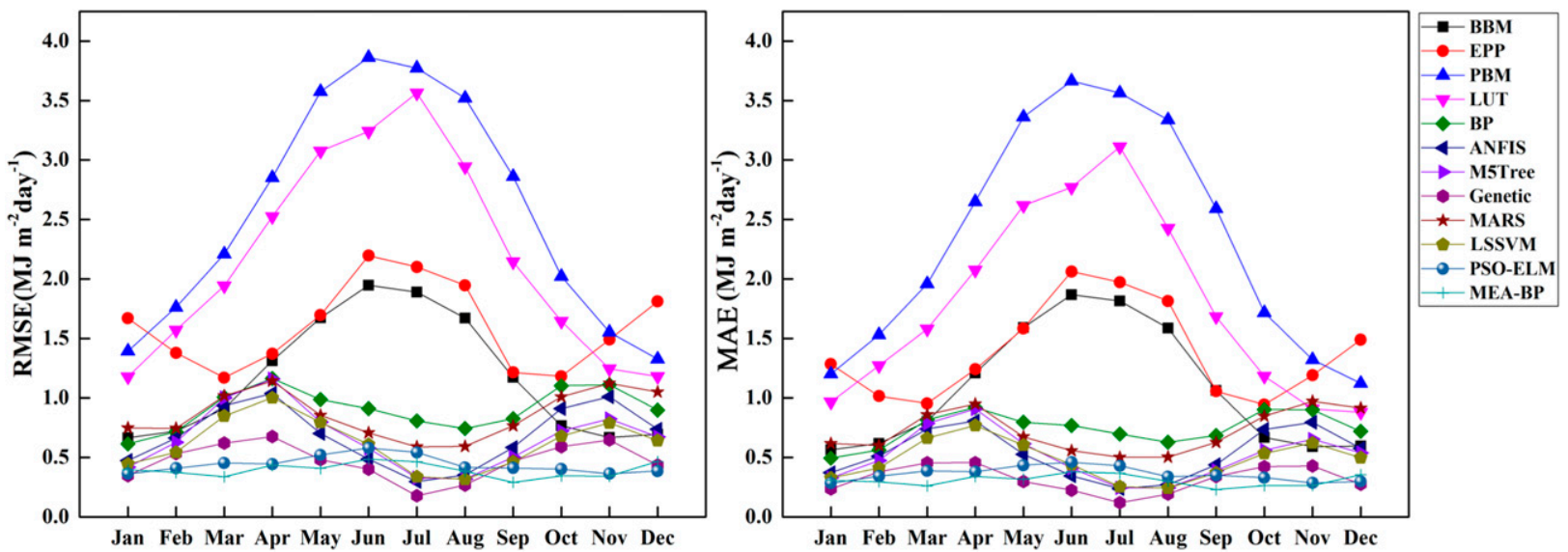

FIG. 7. Monthly variations of RMSE and MAE for BBM, PBM, EPP, and LUT.

frequent cloud occurrences and abundant $w$ in summer. The model performances for BBM performed better than other physically based models; the smallest MAE and RMSE for BBM were 0.565 and $0.666 \mathrm{MJ} \mathrm{m}^{-2}$ day $^{-1}$ in January, respectively, whereas the largest MAE and RMSE for BBM were 1.868 and $1.947 \mathrm{MJ} \mathrm{m}^{-2} \mathrm{day}^{-1}$ in June. PBM was the model with the poorest performance in all 12 selected PAR models. The largest monthly deviation for PBM was found in June, with MAE and RMSE of 3.863 and $3.665 \mathrm{MJ} \mathrm{m}^{-2}$ day $^{-1}$, respectively; the smallest monthly deviation for PBM was found in December, when MAE and RMSE were 1.395 and $1.2 \mathrm{MJ} \mathrm{m}^{-2} \mathrm{day}^{-1}$, respectively. AI models showed overwhelming accuracy compared to physically based models in different seasons with small deviations and seasonal variations of MAE and RMSE. Among these AI models, the MEA-BP showed better agreement with measurements at CERN stations than other AI models. The ranges of monthly MAE and RMSE for MEABP were $0.260-0.379$ and $0.385-1.328 \mathrm{MJ} \mathrm{m}^{-2} \mathrm{day}^{-1}$, respectively.
The RMSE, $R$, and MAE values, representing the model accuracy for all physically based models and AI models in various climate zones across China, are shown in Figs. 8 and 9, respectively. The model deviations of AI models were significantly lower than physically based models in different temperature and humidity zones, with high $R$ and low MAE/RMSE. Among these AI models, the MEA-BP and PSO-ELM showed higher accuracy than other models, due to their strong adaptability to data fluctuations using an optimized algorithm. The ranges of $R$, MAE, and RMSE for PSO-ELM in different temperature zones were $0.963-0.987,0.392-0.532$, and $0.323-0.435 \mathrm{MJ} \mathrm{m}^{-2}$ day $^{-1}$, respectively; the ranges of $R$, MAE, and RMSE for PSO-ELM in different humidity zones were $0.977-0.988,0.309-0.391$, and $0.370-0.469$ $\mathrm{MJ} \mathrm{m}^{-2}$ day $^{-1}$, respectively. The ranges of $R, \mathrm{MAE}$, and RMSE for MEA-BP in different temperature zones were $0.972-0.992,0.224-0.355$, and $0.300-0.553 \mathrm{MJ} \mathrm{m}^{-2}$ day $^{-1}$, respectively; the ranges of $R$, MAE, and RMSE for MEA-BP in different humidity zones were 0.975-0.991, $0.218-0.371$, and $0.351-0.501 \mathrm{MJ} \mathrm{m}^{-2} \mathrm{day}^{-1}$, respectively.
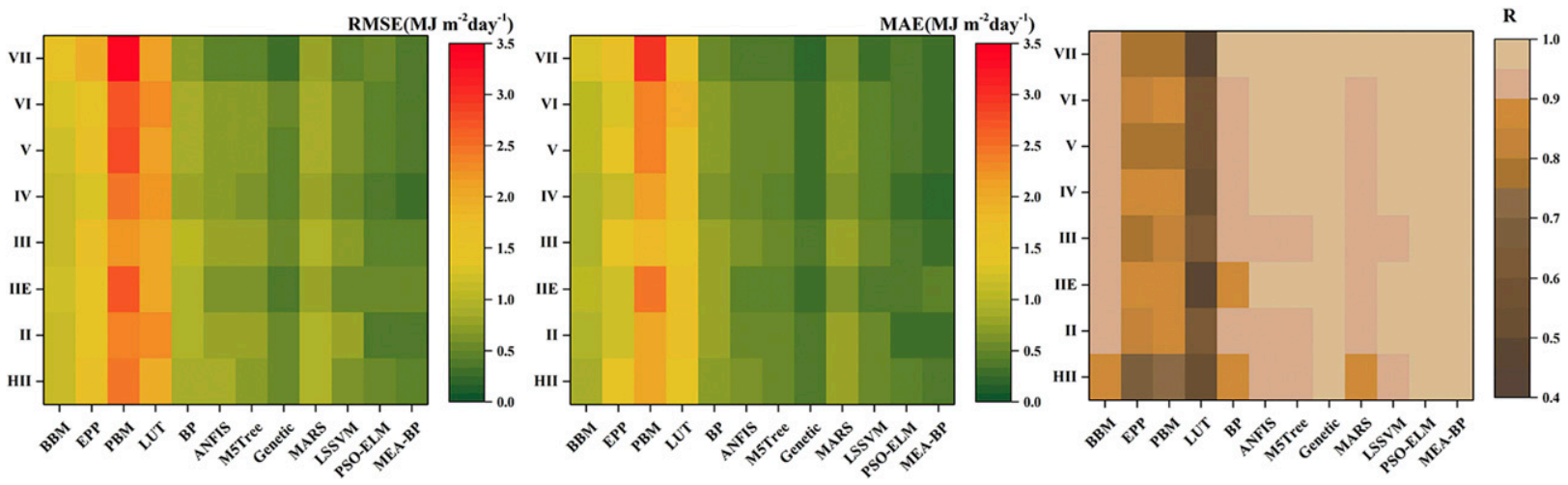

FIG. 8. The RMSE, MAE, and $R$ in different temperature zones. 


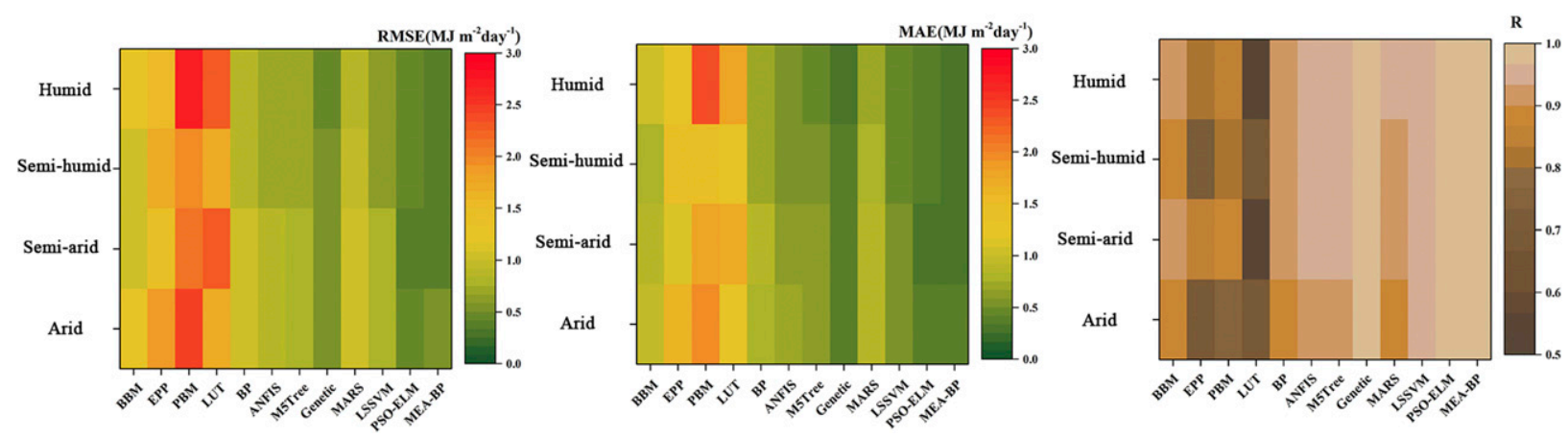

FIG. 9. The RMSE, MAE, and $R$ in different humidity zones.

In all, the MEA-BP model was the PAR model with the highest accuracy and greater robustness than other models in different climate zones with small seasonal distinctions. The MEA-BP model could be used for constructing PAR dataset over mainland China with high accuracy.

\section{c. Constructing a PAR dataset in China}

By applying the optimized BP neural network based on the mind evolutionary algorithm (MEA-BP) to the 2474 CMA routine meteorological stations, we constructed for the first time a high-density dataset of daily PAR over China for the period 1961-2014. The quality control processes were conducted for the estimated PAR dataset (adjusted) following the quality control process in section 2c. About 892 missing values were detected during 1961-2014 at 2474 CMA stations. The temporal and spatial distributions of the missing values (MS) are shown in Fig. 10. The MS were mainly distributed in Sichuan basin and Qinghai-Tibet Plateau, which may be due to the relatively large model errors in these areas (as shown in Table 3).

The homogenization test was conducted using the software package RHtestsV4, which was mainly used for detecting and adjusting for the changepoints in time series databased on the PMT and PMF tests. Unlike the PMF test, the PMT test should be conducted using an additional reference dataset. However, PAR values were only routinely measured at CERN stations. Therefore, the PMF test was chosen to conduct the homogenization test for the PAR dataset generated in this study. Figure 11 showed the numbers of changepoints detected in the PAR data series

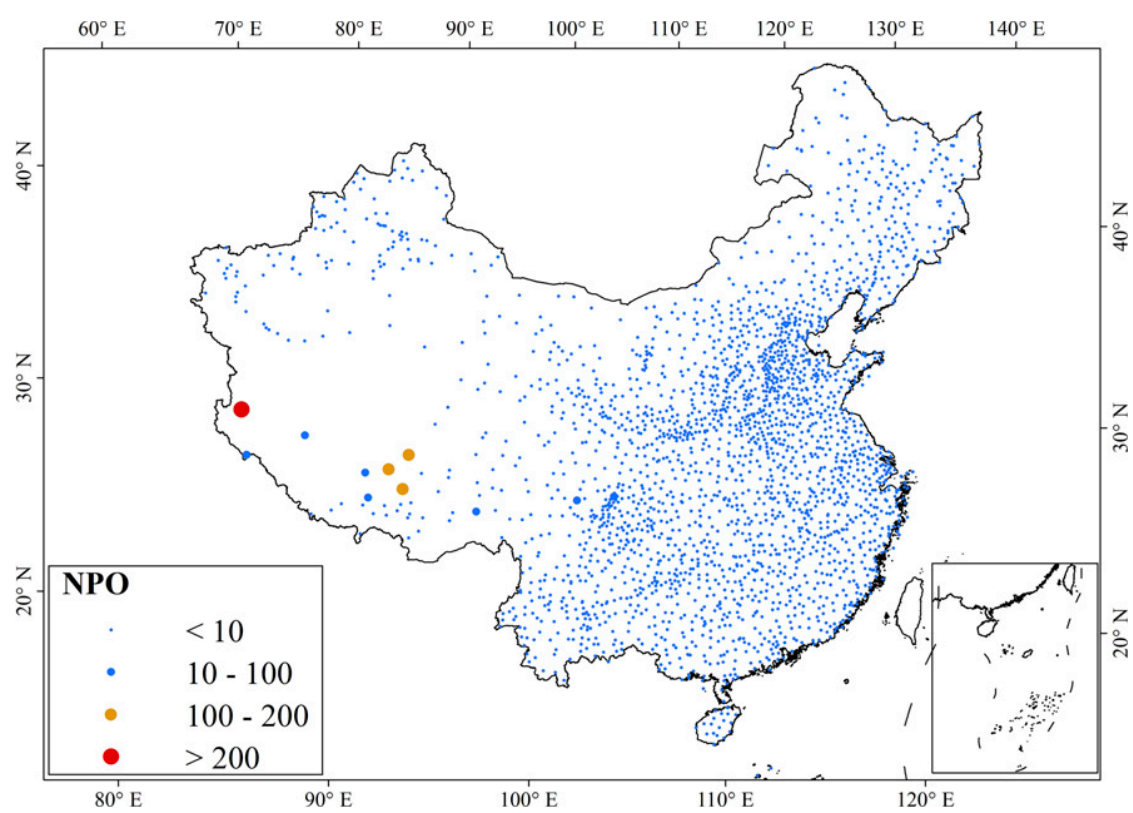

FIG. 10. The number of PAR retrievals that did not pass the data quality control processes (NPO) at 2474 CMA stations in China. 


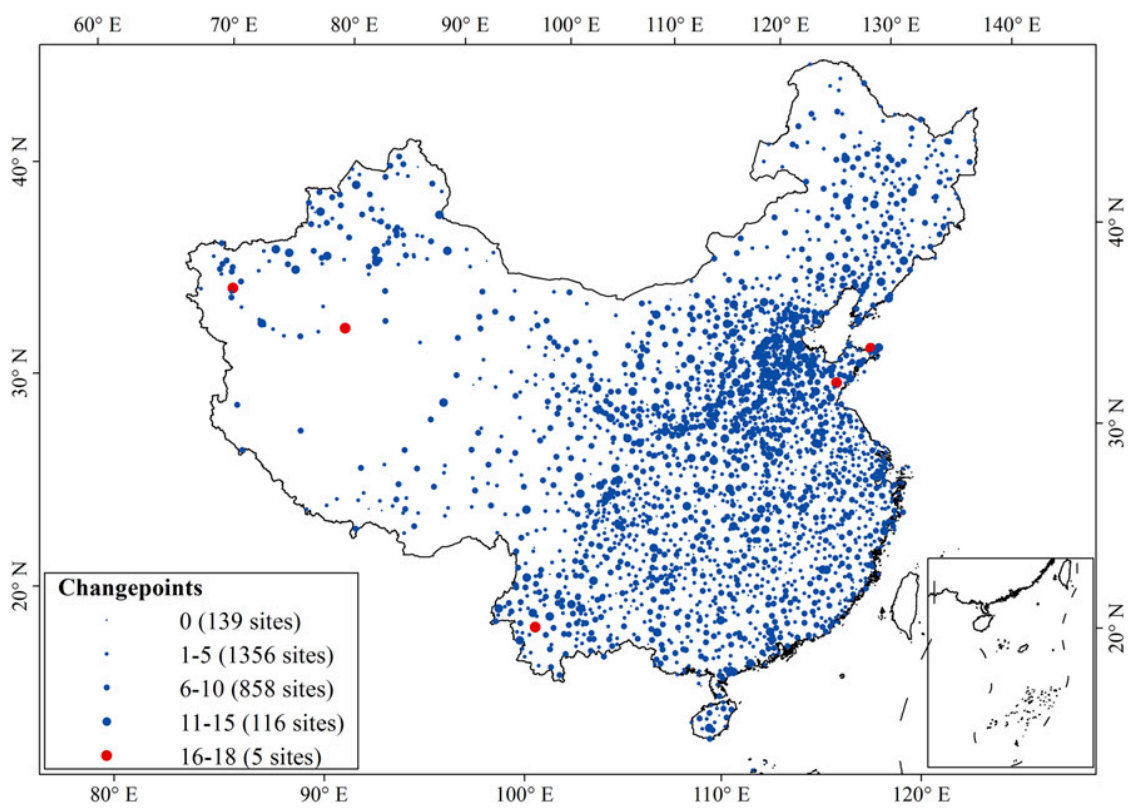

FIG. 11. The number of changepoints detected in the PAR data series during 1961-2014 in China.

during 1961-2014 throughout China. The result showed that 12429 changepoints were detected at 2474 CMA stations. The detailed procedure for the PAR dataset generation was shown in Fig. 12.

Finally, the temporal and spatial characteristics of PAR throughout mainland China were investigated.
Figure 13 showed the spatial characteristics of the annual mean estimated PAR (AMPAR) during 1961-2014 throughout China. AMPAR was relatively higher in western China. The Qinghai-Tibet Plateau was the area with the highest AMPAR $\left(8.976 \mathrm{MJ} \mathrm{m}^{-2}\right.$ day $\left.^{-1}\right)$ across China owing to the small radiation dumping processes.

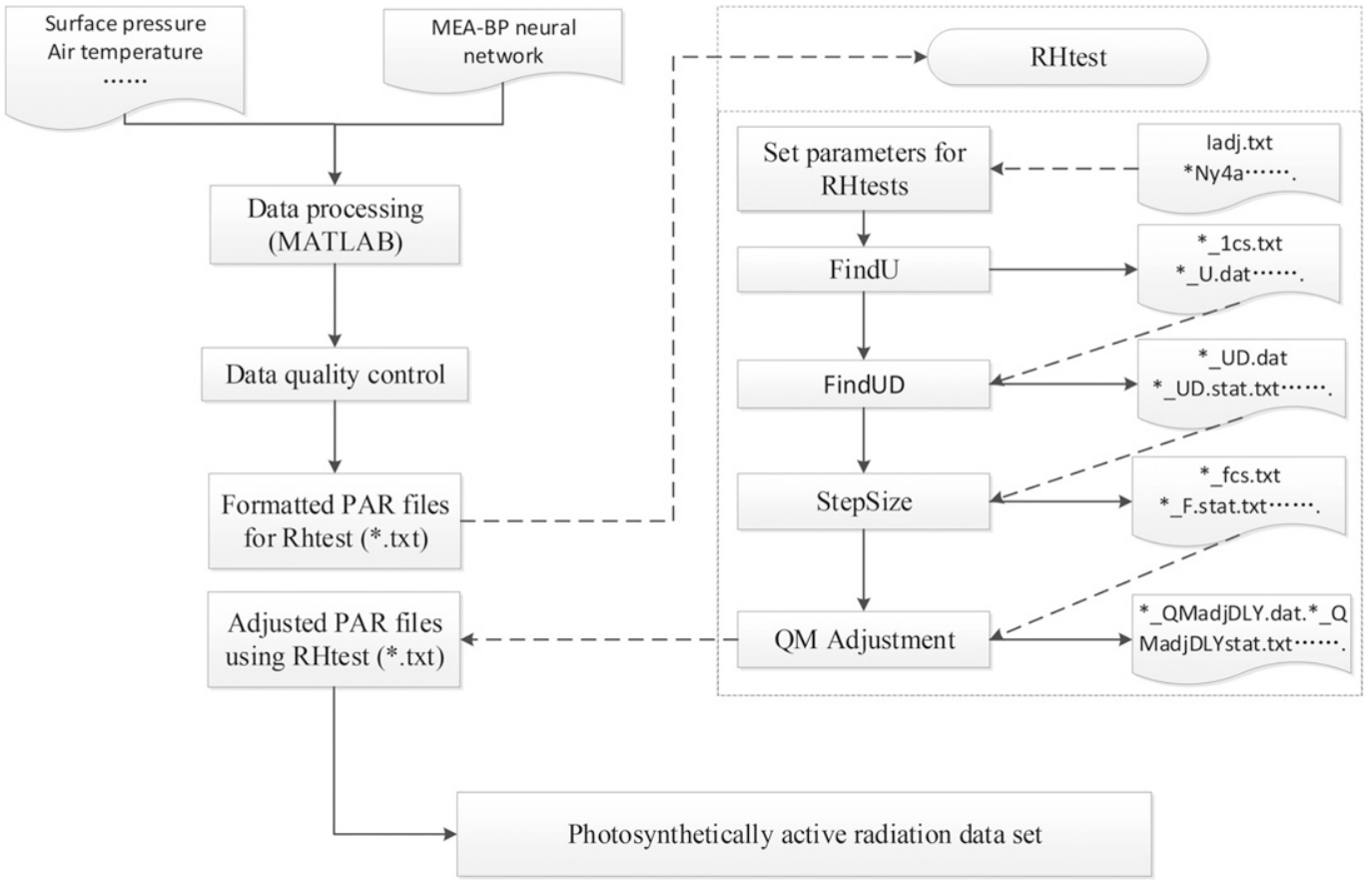

FIG. 12. Flowchart of the generation processes for the PAR dataset. 


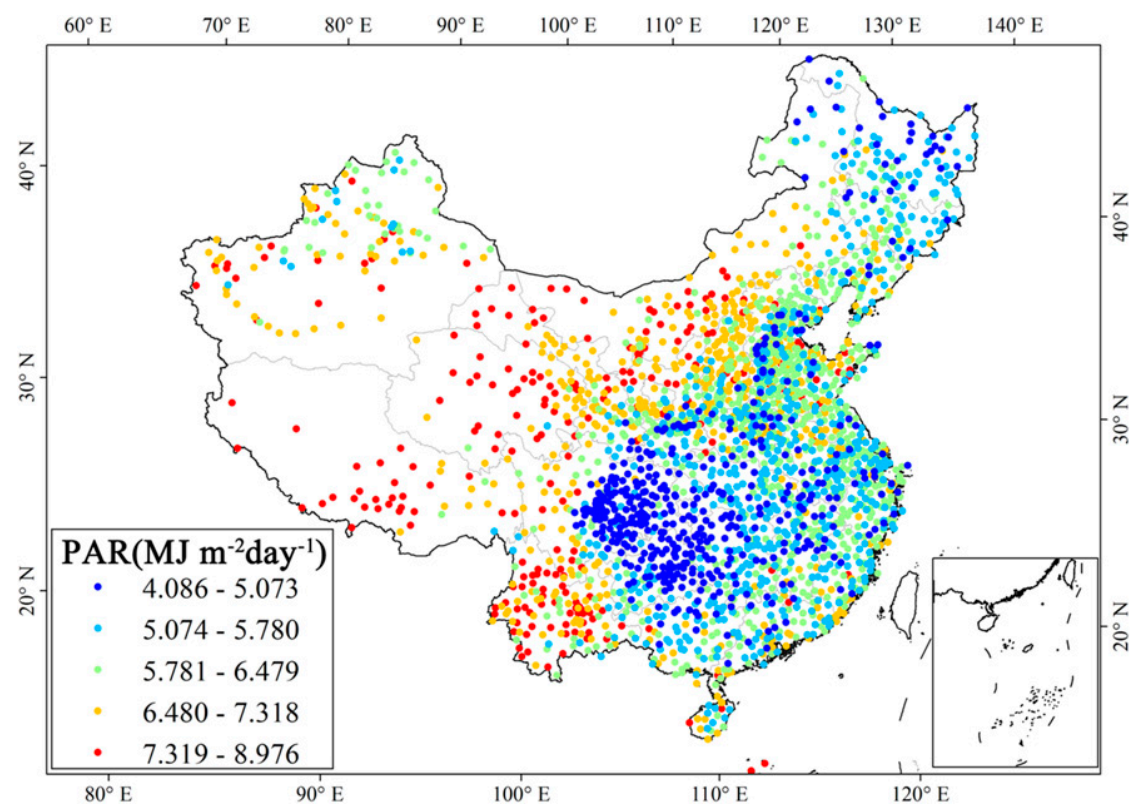

FIG. 13. Spatial distributions of the annual mean PAR during 1961-2014 over China.

In contrast, the Sichuan basin was found to be the area with the lowest AMPAR $\left(4.086 \mathrm{MJ} \mathrm{m}^{-2} \mathrm{day}^{-1}\right)$, due to strong radiation dumping processes.

Figure 14 illustrates the AMPAR and monthly mean PAR (MMPAR) values during 1961-2014 throughout China. The result show that the raw PAR estimations overestimated the PAR values in China, which have been adjusted using the RHtestsV4 packages. The AMPAR values over mainland China gradually decreased during 1961-2014, which may be due to the growing aerosol radiative forcing effects throughout China in recent decades (Qin et al. 2018a). The highest and lowest AMPAR values were found in $1964\left(6.254 \mathrm{MJ} \mathrm{m}^{-2} \mathrm{day}^{-1}\right.$ for adjusted data, $6.059 \mathrm{MJ} \mathrm{m}^{-2} \mathrm{day}^{-1}$ for raw data) and $2012\left(5.796 \mathrm{MJ} \mathrm{m}^{-2} \mathrm{day}^{-1}\right.$ for adjusted data,
$5.837 \mathrm{MJ} \mathrm{m}^{-2} \mathrm{day}^{-1}$ for raw data), respectively. The MMPAR values were higher in summer than that in spring, autumn, and winter, owing to the relatively higher daily $I_{\mathrm{TOA}}$ and longer sunshine hours in summer (Qin et al. 2018b). Then, the anomalous AMPAR values during 1961-2014 in China were calculated to illustrate the temporal trend of AMPAR, which would be more intuitive than that in Fig. 14. The mean AMPAR during $1961-2014$ is $5.979 \mathrm{MJ} \mathrm{m}^{-2} \mathrm{day}^{-1}\left(6.075 \mathrm{MJ} \mathrm{m}^{-2}\right.$ day $^{-1}$ for raw data). Figure 15 shows the anomalous AMPAR values during 1961-2014 over mainland China. It was clear that the anomalous AMPAR showed a growing trend before 1988, whereas the PAR showed a decreasing trend after 1988. The ranges of anomalous AMPAR during 1961-88 for raw data and adjusted data were from -0.109 to 0.328
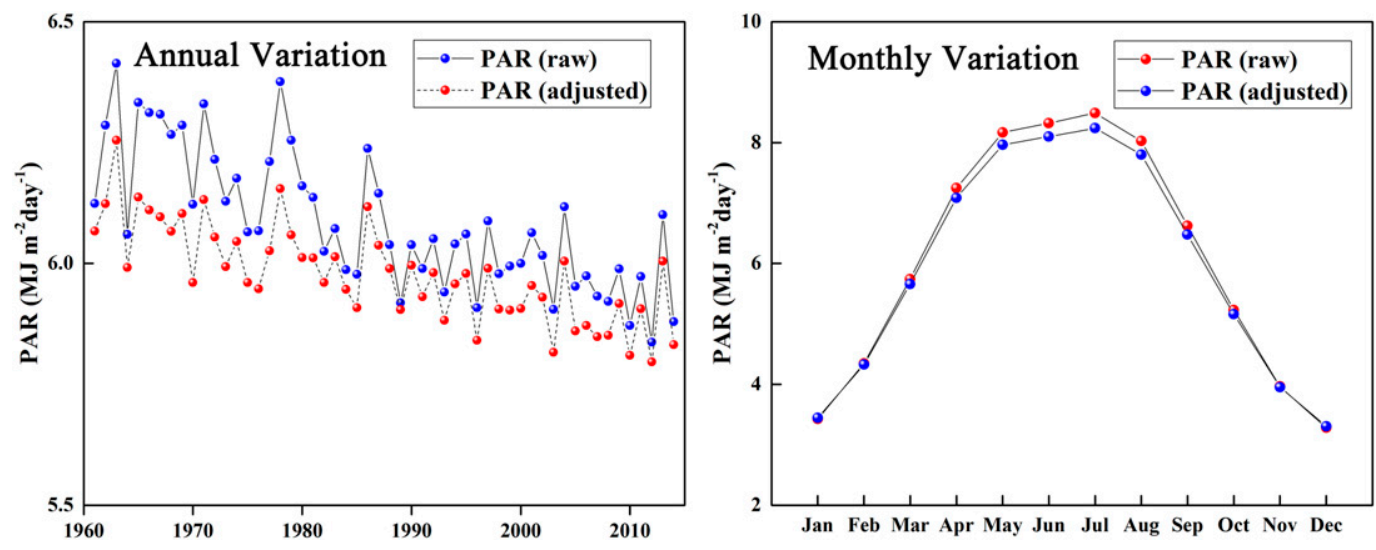

FIG. 14. Annual and monthly variations of PAR during 1961-2014 over China. 


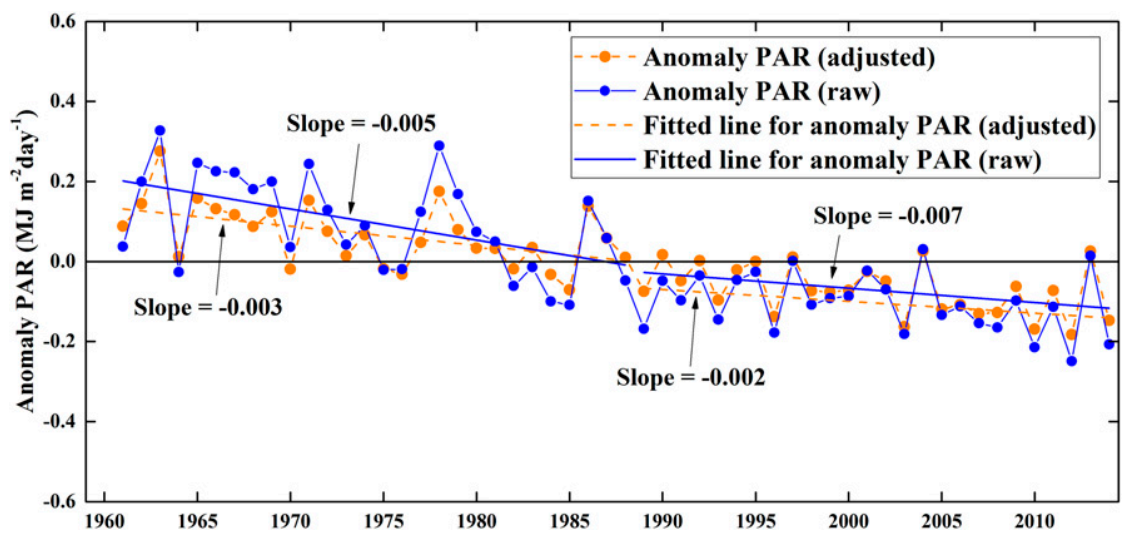

FIG. 15. The anomaly annual mean PAR during 1961-2014 over mainland China.

and from -0.070 to $0.276 \mathrm{MJ} \mathrm{m}^{-2}$ day $^{-1}$, respectively; the ranges of anomalous AMPAR during 1988-2014 for raw data and adjusted data were from -0.249 to 0.031 and from -0.183 to $0.026 \mathrm{MJ} \mathrm{m}^{-2} \mathrm{day}^{-1}$, respectively.

Figures 16 and 17 present the AMPAR and MMPAR in different humidity zones. It was obvious that PAR was significantly positively related to the humidity due to the complicated and strong atmospheric extinction processes in the humid areas. The AMPAR values in arid, semiarid, semihumid, and humid zones were 6.950, 6.923, 6.101, and $5.620 \mathrm{MJ} \mathrm{m}^{-2} \mathrm{day}^{-1}$, respectively. The MMPAR values in different humidity zones were generally higher in summer than other seasons. The ranges of monthly mean PAR in arid, semiarid, semihumid, and humid zones were 3.025-10.776, 3.665-10.063, 3.160-9.059, and $3.307-8.14 \mathrm{MJ} \mathrm{m}^{-2} \mathrm{day}^{-1}$, respectively. The result showed that relatively larger AMPAR values were found in plateau areas, which may be due to relatively weak radiation dumping processes there, for example the mean AMPAR for the plateau sub-frigid zone (HI) and plateau temperate zone (HII) were 7.508 and $7.232 \mathrm{MJ} \mathrm{m}^{-2} \mathrm{day}^{-1}$, respectively. The ranges of monthly mean PAR in HI and HII were 7.184-7.731 and 7.215-7.537 $\mathrm{MJ} \mathrm{m}^{-2}$ day $^{-1}$, respectively. In other temperature zones except $\mathrm{HI}$ and HII, AMPAR values were approximately proportional to the temperature. The smallest AMPAR values were found in cold temperate zone, due to the extremely low temperature compared with other areas; for example the AMPAR for the cold temperate zone (I) was always under the level of $5.5 \mathrm{MJ} \mathrm{m}^{-2}$ day $^{-1}$ during 1961-2014. The range of the monthly mean PAR for I was 4.764$5.43 \mathrm{MJ} \mathrm{m}^{-2}$ day $^{-1}$.

\section{Conclusions}

The accuracy and applicability of 12 selected PAR models were investigated in complicated climatic zones over mainland China. A high-density PAR dataset was constructed using meteorological observations at 2474 CMA stations in China for the first time. The data quality of the PAR dataset was controlled. Meanwhile, a homogenization test using RHtestV4 was conducted.
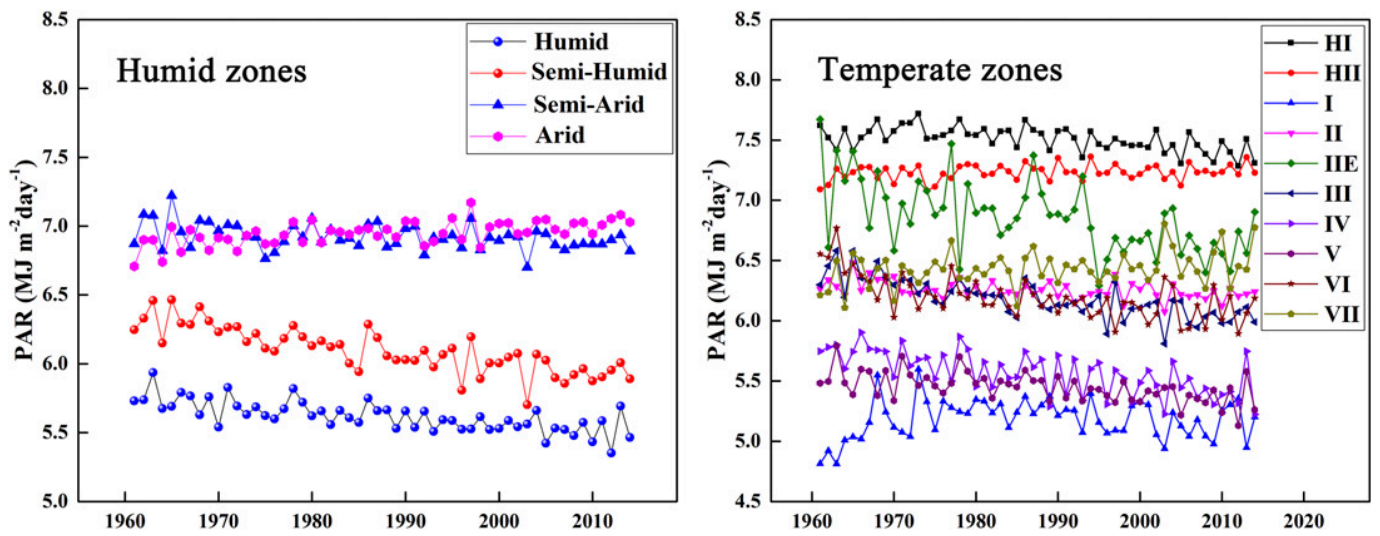

FIG. 16. Annual variations of the AMPAR during 1961-2014 in different climate zones. 

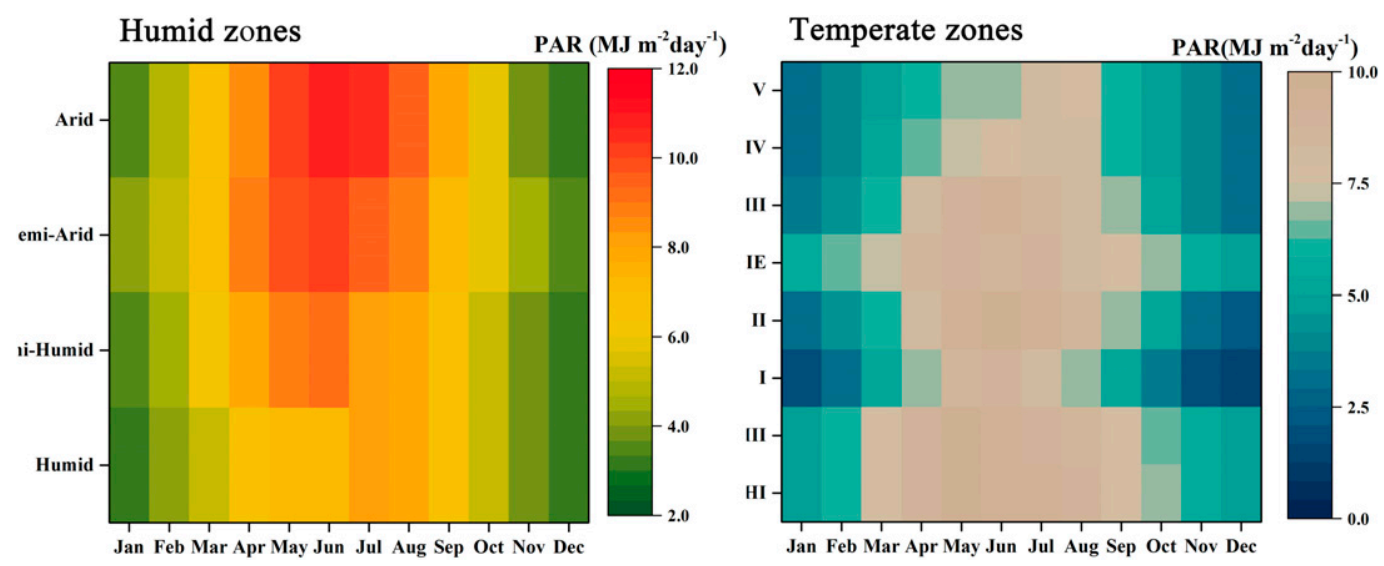

FIG. 17. Monthly variations of PAR during 1961-2014 in different climate zones.

Finally, the temporal and spatial characteristics of PAR throughout China were investigated.

Generally, MEA-BP was the model with the highest accuracy with $R, \mathrm{MBE}$, and RMSE of 0.986 , 0.302 , and $0.393 \mathrm{MJ} \mathrm{m}^{-2} \mathrm{day}^{-1}$, respectively. In terms of the temporal and spatial deviations of model performances at different CERN stations in various temporal zones and humidity zones, the MEA-BP showed the highest accuracy and strongest robustness with small seasonal variations of RMSE, MAE, and $R$. Then, the MEA$\mathrm{BP}$ was used for constructing a high-density PAR dataset throughout China for the first time. The data quality control process and homogenization test on the highdensity PAR datasets were conducted. A total of 12429 changepoints were detected in the dataset at 2474 CMA stations over mainland China. The result indicated that the AMPAR $\left(8.976 \mathrm{MJ} \mathrm{m}^{-2} \mathrm{day}^{-1}\right)$ for Qinghai-Tibet Plateau was also higher than other areas in China, owing to the small radiation dumping process. In contrast, the AMPAR $\left(4.086 \mathrm{MJ} \mathrm{m}^{-2} \mathrm{day}^{-1}\right)$ in the Sichuan basin was always lower than other areas in China. The PAR over mainland China was larger in summer than that in spring, autumn, or winter. The largest monthly mean PAR was found in July $\left(8.486 \mathrm{MJ} \mathrm{m}^{-2}\right.$ day $^{-1}$ for raw data, $8.239 \mathrm{MJ} \mathrm{m}^{-2}$ day $^{-1}$ for adjusted data), whereas the smallest monthly mean PAR was in December $\left(3.281 \mathrm{MJ} \mathrm{m}^{-2} \mathrm{day}^{-1}\right.$ for raw data, $3.305 \mathrm{MJ} \mathrm{m}^{-2}$ day $^{-1}$ for adjusted data). In terms of PAR in different humid zones, the PAR over mainland China was higher in arid zones (dry air condition with a weak radiation dumping process) than that in humid zones (humid air condition with a strong radiation dumping process). The annual mean PAR values in arid, semiarid, semihumid, and humid zones were 6.950, 6.923, 6.101, and $5.620 \mathrm{MJ} \mathrm{m}^{-2}$ day $^{-1}$, respectively. In terms of PAR in different temperature zones, the larger and smaller annual mean PAR values were mainly found in $\mathrm{HI}$ and $\mathrm{I}$, respectively.
The ranges of annual mean PAR for HI and I were 7.1847.731 and $4.764-5.43 \mathrm{MJ} \mathrm{m}^{-2}$ day $^{-1}$, respectively.

Certainly, the RH test on the PAR dataset could be further conducted using reliable reference data. The physical theoretical basis of AI model is controversial ("black box model"), although AI models performed better than physically based models in this study. The advantages of physically based models (which restrict the physical theoretical basis) and AI models (great selflearning ability) could be further integrated to strengthen the theoretical basis and improve the accuracy and robustness of existing PAR models. Moreover, the parameter selection and tuning could be further improved, and a gridded dataset will be generated using a state-of-the-art downscaling method in future work.

Acknowledgments. This work was financially supported by the National Natural Science Foundation of China (41601044), the Special Fund for Basic Scientific Research of Central Colleges, China University of Geosciences, Wuhan (CUG15063, CUGL170401, and CUGCJ1704), the Strategic Priority Research Program of the Chinese Academy of Sciences, Grant XDA19020303, the Opening Foundation of Key Laboratory of Middle Atmosphere and Global environment Observation (LAGEO), Institute of Atmospheric Physics, Chinese Academy of Sciences. We thank the China Meteorological Administration (CMA) for providing the meteorological and radiation data. The authors declare no conflict of interest.

\section{REFERENCES}

Alados, I., I. Foyo-Moreno, and L. Alados-Arboledas, 1996: Photosynthetically active radiation: Measurements and modelling. Agric. For. Meteor., 78, 121-131, https://doi.org/10.1016/01681923(95)02245-7. 
Bergstra, J., R. Bardenet, Y. Bengio, and B. Kégl, 2011: Algorithms for hyper-parameter optimization. 2011 Int. Conf. on Neural Information Processing Systems, Granada, Spain, NIPS Foundation, 2546-2554, https://papers.nips.cc/paper/4443-algorithmsfor-hyper-parameter-optimization.pdf.

Claesen, M., and B. De Moor, 2015: Hyperparameter search in machine learning. 11th Metaheuristics Int. Conf., Agadir, Morocco, CNRS, https://arxiv.org/abs/1502.02127.

Dombi, G. W., P. Nandi, J. M. Saxe, A. M. Ledgerwood, and C. E. Lucas, 1995: Prediction of rib fracture injury outcome by an artificial neural network. J. Trauma, 39, 915-921, https:// doi.org/10.1097/00005373-199511000-00016.

Dye, D. G., 2004: Spectral composition and quanta-to-energy ratio of diffuse photosynthetically active radiation under diverse cloud conditions. J. Geophys. Res., 109, D10203, https:// doi.org/10.1029/2003JD004251.

Eck, T. F., and D. G. Dye, 1991: Satellite estimation of incident photosynthetically active radiation using ultraviolet reflectance. Remote Sens. Environ., 38, 135-146, https://doi.org/ 10.1016/0034-4257(91)90075-H.

Feng, L., W. Qin, L. Wang, A. Lin, and M. Zhang, 2018: Comparison of artificial intelligence and physical models for forecasting photosynthetically active radiation. Remote Sensing, 10, 1855, https://doi.org/10.3390/rs10111855.

Friedman, J. H., 1991: Multivariate adaptive regression splines. Ann. Stat., 19, 1-67, https://doi.org/10.1214/aos/1176347963.

Gao, J., X. Huang, X. Ma, Q. Feng, T. Liang, and H. Xie, 2017: Snow disaster early warning in pastoral areas of Qinghai Province, China. Remote Sens., 9, 475, https://doi.org/10.3390/ rs9050475.

Gueymard, C., 1989: A two-band model for the calculation of clear sky solar irradiance, illuminance, and photosynthetically active radiation at the earth's surface. Sol. Energy, 43, 253-265, https://doi.org/10.1016/0038-092X(89)90113-8.

_ 1995: SMARTS2: A simple model of the atmospheric radiative transfer of sunshine: Algorithms and performance assessment. Florida Solar Energy Center, 78 pp., www.fsec.ucf. edu/en/publications/pdf/fsec-pf-270-95.pdf.

Holland, J. H., 1962: Outline for a logical theory of adaptive systems. J. Assoc. Comput. Mach., 9, 297-314, https://doi.org/ 10.1145/321127.321128.

_- 1992: Adaptation in Natural and Artificial Systems. MIT Press, $211 \mathrm{pp}$.

Hoyle, C. R., G. Myhre, and I. S. A. Isaksen, 2009: Present-day contribution of anthropogenic emissions from China to the global burden and radiative forcing of aerosol and ozone. Tellus., 61B, 618-624, https://doi.org/10.1111/j.1600-0889.2009.00424.x.

Huang, G.-B., Q.-Y. Zhu, and C.-K. Siew, 2006: Extreme learning machine: Theory and applications. Neurocomputing, 70, 489501, https://doi.org/10.1016/j.neucom.2005.12.126.

_ H. Zhou, X. Ding, and R. Zhang, 2012: Extreme learning machine for regression and multiclass classification. IEEE Trans. Syst. Man Cybern., 42B, 513-529, https://doi.org/ 10.1109/TSMCB.2011.2168604.

Jang, J.-S. R., 1991: Fuzzy modeling using generalized neural networks and Kalman filter algorithm. 1991 Natl. Conf. on Artificial Intelligence, Anaheim, CA, AAAI, 762-767, https:// www.aaai.org/Papers/AAAI/1991/AAAI91-119.pdf.

Janjai, S., and R. Wattan, 2011: Development of a model for the estimation of photosynthetically active radiation from geostationary satellite data in a tropical environment. Remote Sens. Environ., 115, 1680-1693, https://doi.org/10.1016/ j.rse.2011.02.026.
Kisi, O., 2014: Modeling solar radiation of Mediterranean region in Turkey by using fuzzy genetic approach. Energy, 64, 429-436, https://doi.org/10.1016/j.energy.2013.10.009.

Kumar, M., and I. N. Kar, 2009: Non-linear HVAC computations using least square support vector machines. Energy Convers. Manage., 50, 1411-1418, https://doi.org/10.1016/j.enconman. 2009.03.009.

Li, L., Y. Du, Y. Tang, and Q. Liu, 2012: A study of fraction of absorbed photosynthetically active radiation characteristics based on SAIL model simulation. Proc. SPIE, 8524, 85242J, https://doi.org/10.1117/12.977769.

— X. X. Xin, H. Zhang, J. Yu, Q. Liu, S. Yu, and J. Wen, 2015: A method for estimating hourly photosynthetically active radiation (PAR) in China by combining geostationary and polarorbiting satellite data. Remote Sens. Environ., 165, 14-26, https://doi.org/10.1016/j.rse.2015.03.034.

Liang, S., T. Zheng, R. Liu, H. Fang, S. Tsay, and S. Running, 2006: Estimation of incident photosynthetically active radiation from Moderate Resolution Imaging Spectrometer data. J. Geophys. Res., 111, D15208, https://doi.org/10.1029/2005JD006730.

, D. Wang, K. Wang, R. Liu, S. Tsay, S. Running, and J. Townshend, 2007: Mapping high-resolution incident photosynthetically active radiation over land from polar-orbiting and geostationary satellite data. Photogramm. Eng. Remote Sensing, 73, 1085-1089.

_- and Coauthors, 2013: A long-term Global Land Surface Satellite (GLASS) data-set for environmental studies. Int. J. Digit. Earth, 6, 5-33, https://doi.org/10.1080/17538947.2013.805262.

López, G., M. A. Rubio, M. Martínez, and F. J. Batlles, 2001: Estimation of hourly global photosynthetically active radiation using artificial neural network models. Agric. For. Meteor., 107, 279-291, https://doi.org/10.1016/S0168-1923(01)00217-9.

McCree, K. J., 1966: A solarimeter for measuring photosynthetically active radiation. Agric. Meteor., 3, 353-366, https:// doi.org/10.1016/0002-1571(66)90017-3.

Moon, P., 1940: Proposed standard solar-radiation curves for engineering use. J. Franklin Inst., 230, 583-617, https://doi.org/ 10.1016/S0016-0032(40)90364-7.

Nasahara, K. N., 2009: Simple algorithm for estimation of photosynthetically active radiation (PAR) using satellite data. Sci. Online Lett. Atmos., 5, 37-40, https://doi.org/10.2151/sola.2009-010.

Pinker, R. T., and I. Laszlo, 1992: Global distribution of photosynthetically active radiation as observed from satellites. J. Climate, 5, 56-65, https://doi.org/10.1175/1520-0442(1992) 005<0056:GDOPAR $>2.0 . \mathrm{CO} ; 2$.

Qin, J., K. Yang, S. Liang, and W. Tang, 2012: Estimation of daily mean photosynthetically active radiation under all-sky conditions based on relative sunshine data. J. Appl. Meteor. Climatol., 51, 150-160, https://doi.org/10.1175/JAMC-D-10-05018.1.

Qin, W., L. Wang, A. Lin, M. Zhang, and M. Bilal, 2018a: Improving the estimation of daily aerosol optical depth and aerosol radiative effect using an optimized artificial neural network. Remote Sens., 10, 1022, https://doi.org/10.3390/rs10071022.

,,,--- X. Xia, B. Hu, and Z. Niu, 2018b: Comparison of deterministic and data-driven models for solar radiation estimation in China. Renew. Sustain. Energy Rev., 81, 579-594, https://doi.org/10.1016/j.rser.2017.08.037.

Quinlan, J. R., 2006: Learning with continuous classes 2. Constructing model trees. Proc. Australian Joint Conf. on Artificial Intelligence, Hobart, Australia, 343-348.

Rahimikhoob, A., M. Asasdi, and M. Mashal, 2013: A comparison between conventional and M5 model tree methods for converting pan evaporation to reference evapotranspiration for 
semi-arid region. Water Resour. Manage., 27, 4815-4826, https://doi.org/10.1007/s11269-013-0440-y.

Samui, P., 2012: Determination of ultimate capacity of driven piles in cohesionless soil: A multivariate adaptive regression spline approach. Int. J. Numer. Anal. Methods Geomech., 36, 14341439, https://doi.org/10.1002/nag.1076.

Singh, K. P., S. N. Bhardwaj, and M. Singh, 1987: Parameters controlling crop growth-rate and their relationship with photosynthetically active radiation and temperature in upland cotton. Indian J. Agric. Sci., 57, 828-832.

Snoek, J., H. Larochelle, and R. P. Adams, 2012: Practical Bayesian optimization of machine learning algorithms. 26th Conf. on Neural Information Processing Systems, Lake Tahoe, NV, NIPS, 2951-2959.

Solomatine, D. P., and Y. Xue, 2004: M5 model trees and neural networks: Application to flood forecasting in the upper reach of the Huai River in China. J. Hydrol. Eng., 9, 491-501, https:// doi.org/10.1061/(ASCE)1084-0699(2004)9:6(491).

Sun, Z., J. Liu, X. Zeng, and H. Liang, 2012: Parameterization of instantaneous global horizontal irradiance: Cloudy-sky component. J. Geophys. Res., 117, D14202, https://doi.org/10.1029/ 2012JD017557.

Tang, W., J. Qin, K. Yang, X. Niu, X. Zhang, Y. Yu, and X. Zhu, 2013: Reconstruction of daily photosynthetically active radiation and its trends over China. J. Geophys. Res. Atmos., 118, 13 292-13 302, https://doi.org/10.1002/2013JD020527.

$\ldots,-,-, \ldots$, M. Min, and S. Liang, 2017: An efficient algorithm for calculating photosynthetically active radiation with MODIS products. Remote Sens. Environ., 194, 146-154, https://doi.org/10.1016/j.rse.2017.03.028.

Wandji Nyamsi, W. W., B. Espinar, P. Blanc, and L. Wald, 2015: Estimating the photosynthetically active radiation under clear skies by means of a new approach. Adv. Sci. Res., 12, 5-10, https://doi.org/10.5194/asr-12-5-2015.

Wang, L., W. Gong, C. Li, A. Lin, B. Hu, and Y. Ma, 2013: Measurement and estimation of photosynthetically active radiation from 1961 to 2011 in central China. Appl. Energy, 111, 1010-1017, https://doi.org/10.1016/j.apenergy.2013.07.001.

, _ _ B. Bu, and Z. Zhu, 2015: Analysis of photosynthetically active radiation in northwest China from observation and estimation. Int. J. Biometeor., 59, 193-204, https://doi.org/ 10.1007/s00484-014-0835-3.
— O. Kisi, M. Zounemat-Kermani, B. Hu, and W. Gong, 2016a: Modeling and comparison of hourly photosynthetically active radiation in different ecosystems. Renew. Sustain. Energy Rev., 56, 436-453, https://doi.org/10.1016/j.rser.2015.11.068.

,,,--- G. A. Salazar, Z. Zhu, and W. Gong, 2016b: Solar radiation prediction using different techniques: Model evaluation and comparison. Renew. Sustain. Energy Rev., 61, 384397, https://doi.org/10.1016/j.rser.2016.04.024.

Wang, X. L., 2008: Penalized maximal F test for detecting undocumented mean shift without trend change. J. Atmos. Oceanic Technol., 25, 368-384, https://doi.org/10.1175/ 2007JTECHA982.1.

—, H. Chen, Y. Wu, Y. Feng, and Q. Pu, 2010: New techniques for the detection and adjustment of shifts in daily precipitation data series. J. Appl. Meteor. Climatol., 49, 2416-2436, https:// doi.org/10.1175/2010JAMC2376.1.

Ying, Z., W. Hong-wei, W. Yu-bing, and G. Peng-cheng, 2017: A novel optimization algorithm for BP neural network based on RS-MEA. Second Int. Conf. on Image, Vision and Computing (ICIVC), Chengdu, China, IEEE, 1073-1078, https://doi.org/ 10.1109/ICIVC.2017.7984719.

Yu, X., Z. Wu, W. Jiang, and X. Guo, 2015: Predicting daily photosynthetically active radiation from global solar radiation in the contiguous United States. Energy Convers. Manage., 89, 71-82, https://doi.org/10.1016/j.enconman.2014.09.038.

Zhang, X., S. Liang, G. Zhou, H. Wu, and X. Zhao, 2014: Generating Global Land Surface Satellite incident shortwave radiation and photosynthetically active radiation products from multiple satellite data. Remote Sens. Environ., 152, 318-332, https://doi.org/10.1016/j.rse.2014.07.003.

Zhao, Y., X. Ren, Y. Hu, J. Wang, and X. Bao, 2016: CNC thermal compensation based on mind evolutionary algorithm optimized BP neural network. World J. Eng. Technol., 4, 38-44, https://doi.org/10.4236/wjet.2016.41004.

Zheng, T., and S. Liang, 2011: A Bayesian approach to integrate satellite-estimated instantaneous photosynthetically active radiation product for daily value calculation. J. Geophys. Res., 116, D15202, https://doi.org/10.1029/2010JD014642.

Zou, L., L. Wang, L. Xia, A. Lin, B. Hu, and H. Zhu, 2017: Prediction and comparison of solar radiation using improved empirical models and adaptive neuro-fuzzy inference systems. Renew. Energy, 106, 343-353, https://doi.org/10.1016/j.renene.2017.01.042. 